\title{
EXPERIMENTAL TESTING OF JOINTS FOR SEISMIC DESIGN OF LIGHTWEIGHT STRUCTURES. PART 2: BOLTED JOINTS IN STRAPS
}

\author{
Miquel Casafont ${ }^{\mathrm{a}}$, Alfredo Arnedo ${ }^{\mathrm{b}}$, Francesc Roure ${ }^{\mathrm{a}}$, and \\ Antonio Rodríguez-Ferran ${ }^{c \dagger}$ \\ a Departament de Resistència de Materials i Estructures a l'Enginyeria, \\ E.T.S. d'Enginyeria Industrial de Barcelona, \\ Universitat Politècnica de Catalunya, Av. Diagonal 647, 08028, Barcelona, Spain \\ b Departament d'Enginyeria de la Construcció, \\ E.T.S. d'Enginyers de Camins, Canals i Ports de Barcelona, \\ Universitat Politècnica de Catalunya, Jordi Girona 1, 08034, Barcelona, Spain \\ ${ }^{\mathrm{C}}$ Laboratori de Càlcul numèric (LaCàN), Departament de Matemàtica Aplicada III, \\ E.T.S. d'Enginyers de Camins, Canals i Ports de Barcelona, \\ Universitat Politècnica de Catalunya, Jordi Girona 1, 08034, Barcelona, Spain
}

\begin{abstract}
An experimental testing campaign on tensile bolted joints between straps is reported. Two dominant failure modes are identified: (1) tilting, bearing and tearing of the sheets (TS) and (2) tilting, bearing and net section failure (NSF). The analysis in terms of ductility and strength shows that bolted connections are less adequate than screwed connections (reported in Part 1 of this paper) for the seismic design of $x$-braced shear walls in lightweight structures. NSF joints are more ductile than TS joints in the sense that they undergo larger displacements before failure. However, if washers are not used, both types of connections fail before energy dissipation through yielding of the diagonal straps can occur. Some design recommendations to improve the seismic performance of bolted joints, including the use of washers, are given. The accuracy of Eurocode 3 formulas to predict the ultimate load is also analyzed.
\end{abstract}

\section{Keywords:}

Light gauge steel; lightweight steel; seismic design; joints; bolts; experimental research; ductility; failure modes; net section failure; bearing .

\section{Introduction}

A growth in the application of lightweight steel technologies in residential construction has taken place in recent years, together with the development of a significant amount of investigations on the issue, mainly focused on structural

\footnotetext{
* Research supported by the Research Fund for Coal and Steel (grant 7210-PR-377) and the "Ministerio de Educación y Ciencia" (grant DPI2002-12388-E)

${ }^{\dagger}$ Corresponding author. Tel.: +34 934015697 Fax: +3493401 1825 e-mail: antonio.rodriguez-ferran@upc.edu URL: http://www-lacan.upc.edu
} 
questions concerning cold-formed steel members. The main current lines of research in this field can be seen in [1].

This research has allowed improving the existing design guides and standards, which are already giving solutions for the most common problems encountered in the project and construction of lightweight steel buildings. Questions such as materials for cold-formed steel construction, instability of compressed and bent members or connections and fasteners have been largely investigated, and they have already been included in codes for design. However, there are still some specific issues that clearly deserve more research. As pointed out in the first part of this paper [2], this is the case of the seismic performance of lightweight structures, which is also the object of study of the investigation presented herein.

Actually, the paper shows a part of a rather extensive experimental and numerical [3] research on the behaviour of dissipative $x$-braced shear walls. The investigation comprises from the experimental study of strap-to-strap connections to tests of full $x$ braced frames. The seismic performance of these frames depends mainly on the strength of their components. Members and connections should be strong enough to allow the dissipative yielding of the $x$ bracings [4].

The investigation is focused on connections. The main objectives are, on the one side, to gain knowledge about their ducti lity and their behaviour under cyclic loads; and, on the other side, to identify which type of joints are most suitable for seismic actions, i.e., to know which are the joints that have enough strength to allow the dissipative yielding of diagonal straps.

The initial steps of the investigation were presented in a previous paper [2], devoted to experimental testing of screwed connections subjected to shear loading. The main conclusion of the analysis of the experimental data is that the mode of failure is a key issue in seismic design of joints. It is verified that screwed connections should be designed to fail in the net-section failure mode, because it is the most ductile type of failure and because it takes place after the yielding of the straps.

In view of this result, it seems that reliable equations to predict the mode of failure of a joint are needed to tackle the design of $x$-braced frames. That is the reason why part of the first paper is also devoted to verify de accuracy of the current Eurocode 3 Part 1-3 proposals for the calculation of joint resistance. It should be pointed out that the Eurocode 3 formulas for the net-section mode of failure showed to work satisfactory, while the bearing formulas gave rather conservative predictions for some of the screwed joints.

The second part of the investigation, presented in this paper, is focused on bolted connections subjected to shear loading. The analysis of the joint behaviour is based on the results of a testing campaign performed in the framework of the RFCS research project "Seismic design of Light Gauge Steel Framed Buildings". Lap joints between two straps connected by means of two rows of bolts are tested under monotonic and cyclic load, see Fig. 1. 
The objectives and the scheme of the paper are similar to what was done for screwed connections. The goals of the experiments are:

1. Obtain parameters such as the initial stiffness, yielding load, ultimate load and maximum displacement

2. Obtain complete force-displacement $(F-d)$ curves, needed for the finite element modeling of $x$-braced frames [3]

3. Identify the failure modes

After that, we analyze the experimental results in order to:

1. Classify the various failure modes in terms of their seismic suitability (strength and ductility)

2. Determine the relation between parameters in joint design (steel grade, strap thicknesses, number and diameter of bolts,...) and failure mode

3. Compare experimental ultimate loads of the joints to the strengths calculated by means of the Eurocode 3 Part 1.3 design formulas

It will also be very interesting to compare the behaviour of screwed and bolted connections.

An outline of paper follows. The laboratory experiments are described in Sections 2 (Test specimens) and 3 (Test procedure), and the results are summarized in Sections 4 (Monotonic tensile tests) and 5 (Load-unload tensile tests). Three main features are studied: the modes of failure, the forcedisplacement curves, and the ductility and stiffness of the connections. The remainder of the paper is devoted to the analysis of the results. The seismic suitability of the joints is discussed in Section 6. Then, in Section 7, the ultimate loads are compared to the values predicted by the Eurocode. Recommendations for design and the concluding remarks of sections 8 and 9 close the paper.

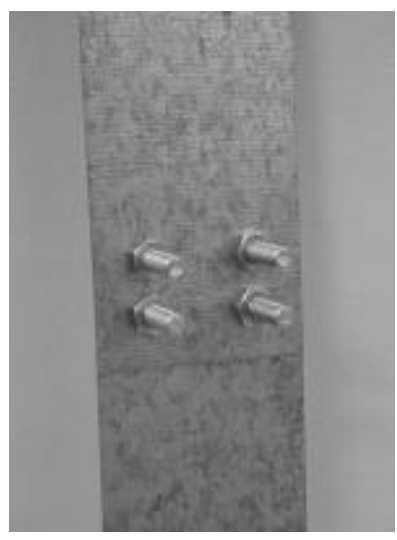

Fig. 1. Bolt joint.

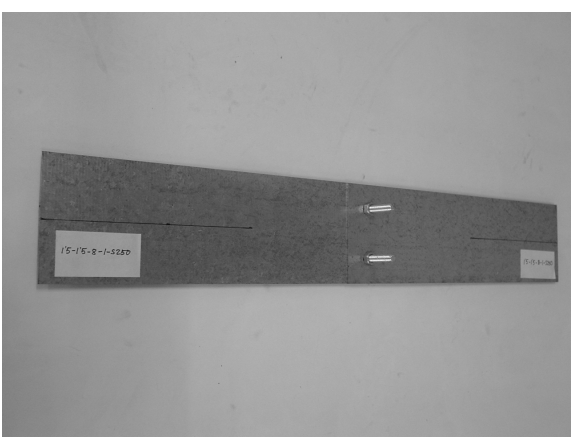

Fig. 2. Specimen ready to be tested.

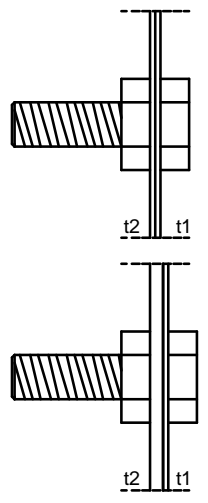

Fig. 3. Strap thickness. 
Table 1. Steel mechanical properties.

$\mathrm{f}_{\mathrm{y}}$ : nominal yield stress, $\mathrm{f}_{\mathrm{u}}$ : nominal ultimate stress, $\mathrm{t}$ : nominal thickness,

$\mathrm{f}_{\mathrm{yt}}$ : measured yield stress, $\mathrm{f}_{\mathrm{ut}}$ : measured ultimate stress.

\begin{tabular}{cccccc}
\hline Steel & $\begin{array}{c}\mathrm{f}_{\mathrm{y}} \\
\left(\mathrm{N} / \mathrm{mm}^{2}\right)\end{array}$ & $\begin{array}{c}\mathrm{f}_{\mathrm{u}} \\
\left(\mathrm{N} / \mathrm{mm}^{2}\right)\end{array}$ & $\begin{array}{c}\mathrm{t} \\
(\mathrm{mm})\end{array}$ & $\begin{array}{c}\mathrm{f}_{\mathrm{yt}} \\
\left(\mathrm{N} / \mathrm{mm}^{2}\right)\end{array}$ & $\begin{array}{c}\mathrm{f}_{\mathrm{ut}} \\
\left(\mathrm{N} / \mathrm{mm}^{2}\right)\end{array}$ \\
\hline S -350 GD+Z & 350 & 420 & 1,5 & 387 & 519 \\
& & & 1 & 392 & 520 \\
S - 250 GD+Z & 250 & 330 & 1 & 385 & 512 \\
\hline
\end{tabular}

\section{Test specimens}

The bolt joints tested are similar to the screw joints of the investigation reported in the first part of the paper (Fig. 1) [2]. For example, the steel grade of the straps is the same, either S $350 \mathrm{GD}+Z$ or S $250 \mathrm{GD}+Z$ [5]. The nominal and mechanical properties of these steels are shown in Table 1. It should be noticed that the experimental $f_{y t}$ and $f_{u t}$ are rather higher than the nominal $f_{y}$ and $f_{u}$.

Bolts of two different diameters are used to connect the straps: $8 \mathrm{~mm}$ and 10 $\mathrm{mm}$. The heads of these bolts are hexagonal and the shafts are threaded all along their length. All the straps of steel grade S $350 \mathrm{GD}+Z$ are connected with washers, while washers are only used in 4 out of the 38 S $250 \mathrm{GD}+Z$ straps. When used, washers of $20 \mathrm{~mm} \Phi$ are placed under the bolt head and nut.

The torque applied to the bolts is not measured. Bolts are tightened by hand using standard tools, so the torque should be small.

The nominal length of the straps is either $350 \mathrm{~mm}$, when connected by means of one column of bolts, or $375 \mathrm{~mm}$, when connected by means of two columns. Their thickness ranges form $0,85 \mathrm{~mm}$ to $1,5 \mathrm{~mm}$, and their width is always the same, $100 \mathrm{~mm}$. The tolerance of the bolt holes drilled in the straps is $1 \mathrm{~mm}$.

Fig. 4 shows the position of the bolts: the spacing and the longitudinal and transverse edge distances. The joint lay out is identical for all the specimens.

The bolt connections are listed in Table 2 together with their main dimensions and test results. The first column of the table shows the joint notation, whose meaning is explained in the following example: 


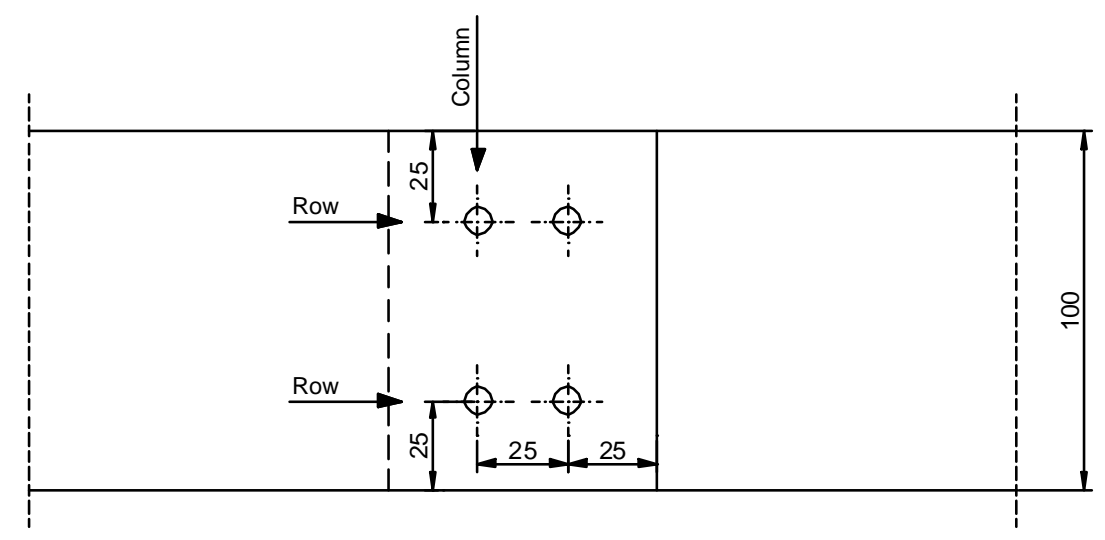

Fig. 4. Joint lay out.

$$
\begin{aligned}
& t_{1}-t_{2}-\Phi-n c-s g-l(W) \\
& 1-1-10-2-S 250-E(W)
\end{aligned}
$$

$t_{1}$ : thickness of the first strap $\left(t_{1}=1 \mathrm{~mm}\right), t_{2}$ : thickness of the second strap $\left(t_{2}=1\right.$ $\mathrm{mm}), \Phi$ : diameter of the bolt $(\Phi=10 \mathrm{~mm})$, nc: number of bolt columns $(\mathrm{nc}=2)$, sg: steel grade (S250 GD+Z), I: letter used when there are two or more identical joints $(E),(W)$ denotes that washers are used.

\section{Test procedure}

Tests are performed applying the same procedure as the one previously followed in the experimental campaign of screw connections [2].

The first operation is to measure the actual dimensions of the joint components (see some of the measured values in Table 2 and the full collection of measurements in [6,7]). Afterwards, the specimens are labelled and a line is drawn along the axis of the straps. This line is used to centre the specimens in the testing machine. Fig. 2 shows a joint ready to be tested.

A $250 \mathrm{kN}$ universal testing machine is used to load the joints. Tests are displacement-controlled and the load is applied at a rate of $0,01 \mathrm{~mm} / \mathrm{s}$ when the elongation of the joint is lower than $2 \mathrm{~mm}$; and at a rate of $0,02 \mathrm{~mm} / \mathrm{s}$ when the elongation is higher.

Every 0,04 millimetres, he applied force $(F)$ and the length increment of the joint (d) are measured and stored in a computer. On the basis of these data, F-d curves, such as the ones shown in Figs. 9 to 14, are drawn. It can be seen that the specimens are loaded until they fail and the measured load is almost zero. 
Table 2. Main dimensions of specimens and results of tests.

$\mathrm{t}_{1 \mathrm{t}}$ : measured $\mathrm{t}_{1}$ thickness (Fig. 3 ), $\mathrm{t}_{2 \mathrm{t}}$ : measured $\mathrm{t}_{2}$ thickness, $\mathrm{a}_{1 \mathrm{t}}$ : measured $\mathrm{a}_{1}$ width, $\mathrm{a}_{2 \mathrm{t}}$ : measured $\mathrm{a}_{2}$ width, Put: measured ultimate load, T: tilting, B: bearing, NSF: net section failure, TS: tearing of the sheet.

\begin{tabular}{|c|c|c|c|c|c|c|}
\hline Connection & $t_{1 t}$ & $t_{2 t}$ & $a_{1 t}$ & $a_{2 t}$ & Failure mode & $\mathrm{P}_{\mathrm{ut}}(\mathrm{N})$ \\
\hline $0,85-0,85-10-2-S 250$ & 0,88 & 0,89 & 100,0 & 100,0 & $\mathrm{~T}+\mathrm{B}+\mathrm{NSF}$ & 22731 \\
\hline $0,85-1-10-2-S 250$ & 0,88 & 1,03 & 100,0 & 100,0 & $\mathrm{~T}+\mathrm{B}+\mathrm{NSF}$ & 23842 \\
\hline $0,85-1,5-10-2-S 250$ & 0,88 & 1,54 & 100,0 & 100,0 & $\mathrm{~T}+\mathrm{B}+\mathrm{NSF}$ & 24450 \\
\hline 1-1-10-2-S250-A & 1,02 & 1,04 & 100,0 & 100,3 & $\mathrm{~T}+\mathrm{B}+\mathrm{NSF}$ & 27884 \\
\hline 1-1-10-2-S250-B & 1,04 & 1,04 & 100,0 & 100,0 & $\mathrm{~T}+\mathrm{B}+\mathrm{NSF}$ & 28160 \\
\hline $1-1-10-2-S 250-C$ & 1,02 & 1,04 & 100,0 & 100,0 & $\mathrm{~T}+\mathrm{B}+\mathrm{NSF}$ & 28095 \\
\hline 1-1-10-2-S250-D & 1,04 & 1,02 & 100,0 & 100,0 & $\mathrm{~T}+\mathrm{B}+\mathrm{NSF}$ & 27828 \\
\hline 1-1-10-2-S250-E(W) & 1,01 & 1,04 & 100,0 & 100,1 & $\mathrm{~T}+\mathrm{B}+\mathrm{NSF}$ & 30039 \\
\hline 1-1-10-2-S250-F(W) & 1,03 & 1,02 & 100,0 & 100,0 & $\mathrm{~T}+\mathrm{B}+\mathrm{NSF}$ & 30746 \\
\hline 1-1-10-2-S250-G & 1,03 & 1,03 & 99,9 & 100,0 & $\mathrm{~T}+\mathrm{B}+\mathrm{NSF}$ & 28332 \\
\hline $1-1,5-10-2-S 250$ & 1,03 & 1,59 & 100,0 & 100,0 & $\mathrm{~T}+\mathrm{B}+\mathrm{NSF}$ & 30112 \\
\hline $1,5-1,5-10-2-S 250$ & 1,57 & 1,59 & 100,0 & 100,0 & $\mathrm{~T}+\mathrm{B}+\mathrm{NSF}$ & 44734 \\
\hline $0,85-0,85-8-2-S 250$ & 0,88 & 0,88 & 100,0 & 100,0 & $\mathrm{~T}+\mathrm{B}+\mathrm{TS}$ & 20529 \\
\hline $0,85-1-8-2-S 250$ & 0,87 & 1,04 & 100,0 & 100,0 & $\mathrm{~T}+\mathrm{B}+\mathrm{NSF}$ & 20433 \\
\hline $0,85-1,5-8-2-S 250$ & 0,88 & 1,59 & 100,0 & 100,0 & $\mathrm{~T}+\mathrm{B}+\mathrm{NSF}$ & 23131 \\
\hline 1-1-8-2-S250-A & 1,03 & 1,04 & 100,0 & 100,0 & $\mathrm{~T}+\mathrm{B}+\mathrm{TS}$ & 22829 \\
\hline 1-1-8-2-S250-B & 1,04 & 1,58 & 100,0 & 100,0 & $\mathrm{~T}+\mathrm{B}+\mathrm{TS}$ & 22441 \\
\hline 1-1,5-8-2-S250 & 1,04 & 1,58 & 100,1 & 100,0 & $\mathrm{~T}+\mathrm{B}+\mathrm{NSF}$ & 28419 \\
\hline $1,5-1,5-8-2-S 250$ & 1,59 & 1,59 & 100,0 & 100,0 & $\mathrm{~T}+\mathrm{B}+\mathrm{TS}$ & 37572 \\
\hline $0,85-0,85-10-1-S 250$ & 0,89 & 0,89 & 100,0 & 100,0 & $\mathrm{~T}+\mathrm{B}+\mathrm{TS}$ & 14335 \\
\hline $0,85-1-10-1-S 250$ & 0,88 & 1,04 & 100,0 & 100,0 & $\mathrm{~T}+\mathrm{B}+\mathrm{TS}$ & 12933 \\
\hline $0,85-1,5-10-1-S 250$ & 0,88 & 1,57 & 100,0 & 100,0 & $\mathrm{~T}+\mathrm{B}+\mathrm{TS}$ & 12508 \\
\hline 1-1-10-1-S250-A & 1,05 & 1,05 & 100,0 & 100,0 & $\mathrm{~T}+\mathrm{B}+\mathrm{TS}$ & 15391 \\
\hline 1-1-10-1-S250-B & 1,05 & 1,04 & 100,0 & 100,0 & $\mathrm{~T}+\mathrm{B}+\mathrm{TS}$ & 15279 \\
\hline 1-1-10-1-S250-C & 1,04 & 1,04 & 100,0 & 100,0 & $\mathrm{~T}+\mathrm{B}+\mathrm{TS}$ & 14395 \\
\hline 1-1-10-1-S250-D & 1,04 & 1,04 & 100,0 & 100,0 & $\mathrm{~T}+\mathrm{B}+\mathrm{TS}$ & 15326 \\
\hline 1-1-10-1-S250-E(W) & 1,04 & 1,03 & 100,0 & 100,0 & $\mathrm{~T}+\mathrm{B}+\mathrm{TS}$ & 17537 \\
\hline 1-1-10-1-S250-F(W) & 1,02 & 1,02 & 100,0 & 100,0 & $\mathrm{~T}+\mathrm{B}+\mathrm{TS}$ & 17865 \\
\hline $1-1-10-1-S 250-G$ & 1,03 & 1,03 & 100,0 & 100,0 & $\mathrm{~T}+\mathrm{B}+\mathrm{TS}$ & 15132 \\
\hline $1-1,5-10-1-S 250$ & 1,05 & 1,59 & 100,0 & 100,0 & $\mathrm{~T}+\mathrm{B}+\mathrm{TS}$ & 14158 \\
\hline $1,5-1,5-10-1-S 250$ & 1,60 & 1,59 & 100,0 & 100,0 & $\mathrm{~T}+\mathrm{B}+\mathrm{TS}$ & 25872 \\
\hline $0,85-0,85-8-1-S 250$ & 0,88 & 0,88 & 100,0 & 100,0 & $\mathrm{~T}+\mathrm{B}+\mathrm{TS}$ & 12374 \\
\hline $0,85-1-8-1-S 250$ & 0,88 & 1,03 & 100,2 & 100,0 & $\mathrm{~T}+\mathrm{B}+\mathrm{TS}$ & 10082 \\
\hline $0,85-1,5-8-1-S 250$ & 0,89 & 1,58 & 100,1 & 100,2 & $\mathrm{~T}+\mathrm{B}+\mathrm{TS}$ & 10344 \\
\hline 1-1-8-1-S250-A & 1,05 & 1,04 & 100,1 & 100,0 & $\mathrm{~T}+\mathrm{B}+\mathrm{TS}$ & 12189 \\
\hline 1-1-8-1-S250-B & 1,04 & 1,04 & 99,9 & 100,0 & $\mathrm{~T}+\mathrm{B}+\mathrm{TS}$ & 12180 \\
\hline 1-1,5-8-1-S250 & 1,04 & 1,57 & 99,9 & 100,1 & $\mathrm{~T}+\mathrm{B}+\mathrm{TS}$ & 13137 \\
\hline $1,5-1,5-8-1-S 250$ & 1,58 & 1,58 & 100,0 & 100,0 & $\mathrm{~T}+\mathrm{B}+\mathrm{TS}$ & 21855 \\
\hline $1-1-10-1-S 350(\mathrm{~W})$ & 0,99 & 0,98 & 100,0 & 100,1 & $\mathrm{~T}+\mathrm{B}+\mathrm{TS}$ & 19575 \\
\hline $1,5-1,5-10-1-S 350(W)$ & 1,48 & 1,48 & 100,2 & 100,2 & $\mathrm{~T}+\mathrm{B}+\mathrm{TS}$ & 45471 \\
\hline 1-1-10-2-S350-A(W) & 0,98 & 0,98 & 100,2 & 100,1 & $\mathrm{~T}+\mathrm{B}+\mathrm{NSF}$ & 39120 \\
\hline 1-1-10-2-S350-B(W) & 0,99 & 0,98 & 100,1 & 100,1 & $\mathrm{~T}+\mathrm{B}+\mathrm{NSF}$ & 38710 \\
\hline $1,5-1,5-10-2-S 350(W)$ & 1,50 & 1,50 & 100,0 & 100,1 & $\mathrm{~T}+\mathrm{B}+\mathrm{NSF}$ & 59690 \\
\hline
\end{tabular}


In the course of an earthquake, displacements change their sign and, as a consequence, joints are subject to reversing movements. For this reason, apart from monotonic tensile tests, load-unload tests are also performed. In these tests, it is particularly important to capture the unloading branch of the cyclic axial load response.

The cyclic tests are carried out unloading four times $b$ a near zero load (see Figs. 23 and 24). Only tension forces are applied to the diagonal straps, because they do not have compression strength. The experimental procedure followed is similar to the one explained above. The only difference is that the unloading process is load-controlled to ensure that the specimens are always in tension and do not become compressed.

\section{Results of monotonic tensile tests}

\subsection{Modes of failure}

The specimens show various phenomena during the tests [8-11]: tilting $(T)$, bearing (B), curling and tearing of the sheets (TS), and net section failure (NSF).

Tilting and bearing are observed in all the joints. Tilting is more evident when the joint connects two straps of the same thickness, while joints connecting two specimens of different thickness are more prone to bearing.

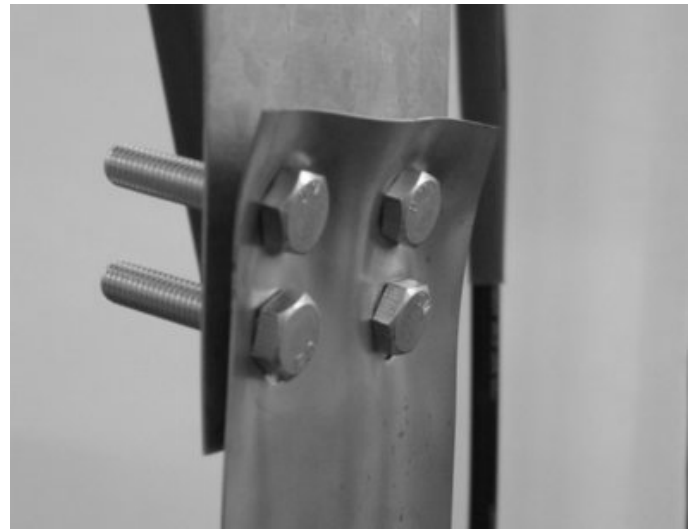

Fig. 5. Tilting + bearing in specimen 0,85-1-10-2-S250.

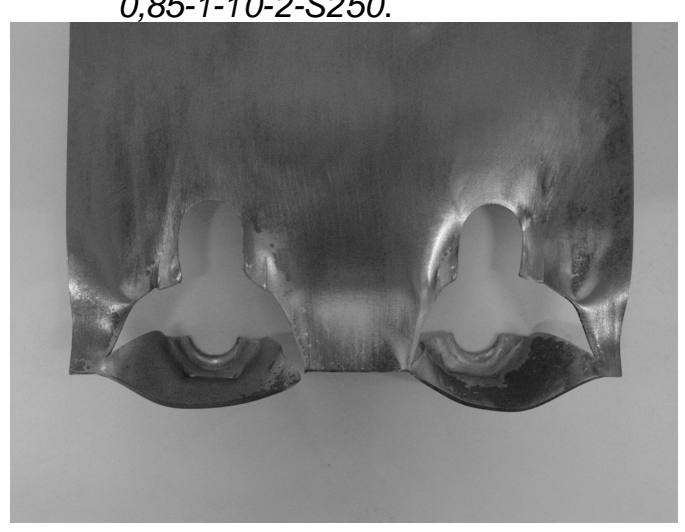

Fig. 7. Bearing failure in specimen 0,85-1,5-10-1-S250.

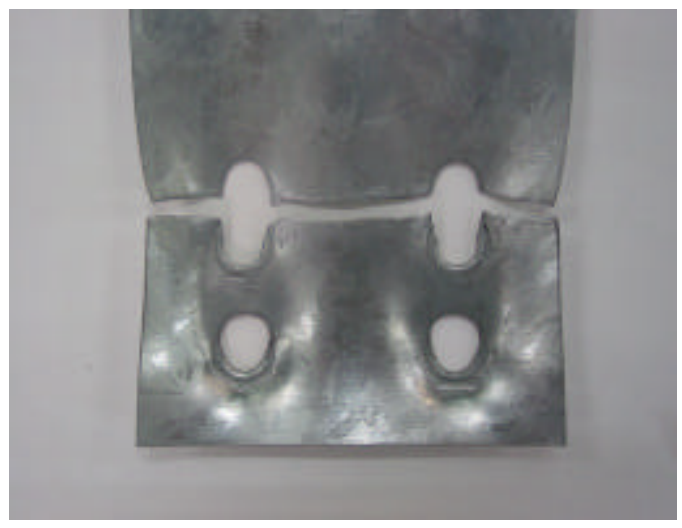

Fig. 6. Net section failure in specimen 1-1.5-10-2-S250.

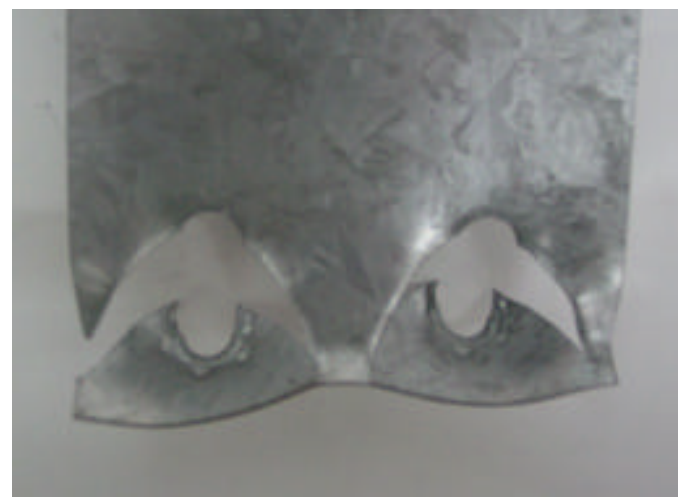

Fig. 8. Bearing failure in specimen 1-1-10-1-S250-A. 
Depending on the final mode of failure, joints can be classified into two groups: joints that fail due to the bearing and tearing phenomena $(T+B+T S)$, and joints that are subjected to net section failure $(\mathrm{T}+\mathrm{B}+\mathrm{NSF})$.

Those joints that fail $\mathrm{T}+\mathrm{B}+\mathrm{NSF}$ show tilting and bearing from the first steps of the loading process (Fig. 5). Afterwards, the failure begins from the center of the original bolt holes, and it propagates perpendicularly to the direction of loading until it reaches the lateral edge of the strap (Fig. 6). Necking of the sheet width in the zone of failure and a small out-of-plane deformation are also observed.

In relation to the bearing failure $(T+B+T S)$, two types of joints may be distinguished (see [11]). On the one hand, there are joints where diagonal tears initiate at the edge of the zone affected by bearing, and advance until the end of the straps with significant curling of the sheet (Fig. 7). This type of bearing failure is mainly observed in joints connecting straps of different thickness. On the other hand, when both straps have the same thickness, tears originate near the center of the bolt holes, in a similar way as in the net section failure mode. In this case, however, tears propagate diagonally and the straps experience considerable curling (Fig. 8).

The number and diameter of bolts and the thickness of the straps are the parameters that determine the modes of failure of the specimens. All the joints with one column of bolts fail bearing $(T+B+T S)$, while the mode of failure of the joints with two columns depends on the diameter of the bolt and the thickness of the straps. Net section failure (T+B+NSF) is observed in joints with two columns of $10 \mathrm{~mm}$ diameter bolts and joints with two columns $8 \mathrm{~mm}$ diameter bolts connecting straps of different thickness. Joints connecting straps of the same thickness by means of two columns of $8 \mathrm{~mm}$ diameter bolts fail $\mathrm{T}+\mathrm{B}+\mathrm{TS}$.

\subsection{Force-displacement curves}

The force-displacement curves of $\mathrm{T}+\mathrm{B}+\mathrm{NSF}$ joints are different from the curves of $\mathrm{T}+\mathrm{B}+\mathrm{TS}$ joints. Figs. 9 and 10 show the F-d curves of two joints that fail $\mathrm{T}+\mathrm{B}+\mathrm{NSF}$. Both have two initial elastic branches, with different stiffness, separated by a small irregular horizo ntal branch that corresponds to the slipping of the straps. Subsequently, the joint yields and the curve either shows a small drop, if one of the straps is thin, $0.85 \mathrm{~mm}$ (Fig. 9), or it goes directly to the hardening branch (Fig. 10). The maximum load is achieved at the end of this hardening branch, which is followed by a sudden failure.

The $A_{g t} \cdot f_{y t}$ line plotted in these figures corresponds to the yielding load of the strap. This value will be used afterwards, when the seismic suitability of the joints is discussed.

Joints connecting two straps by means of one column of bolts, which always fail $\mathrm{T}+\mathrm{B}+\mathrm{TS}$, show F-d curves such as the ones of Figs. 11 and 12. As in the $\mathrm{T}+\mathrm{B}+\mathrm{NSF}$ curves, the slipping and the two initial elastic branches can be seen. These curves also have a well defined first drop after yielding, that is followed 


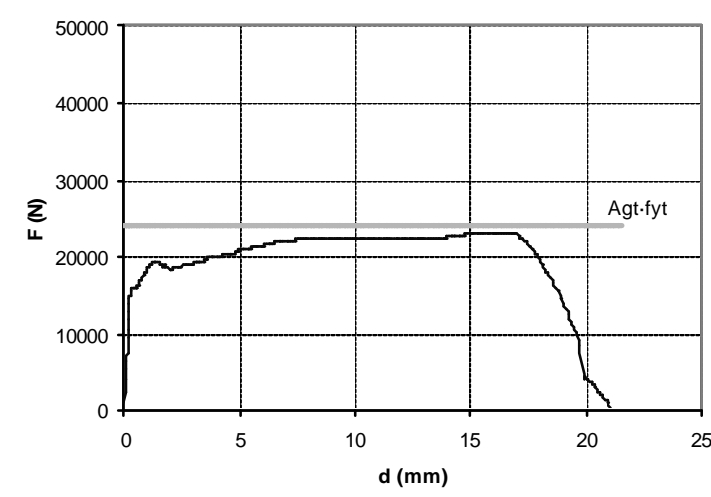

Fig. 9. F-d curve of a $T+B+N S F$ joint. Specimen 0,85-1,5-8-2-S250.

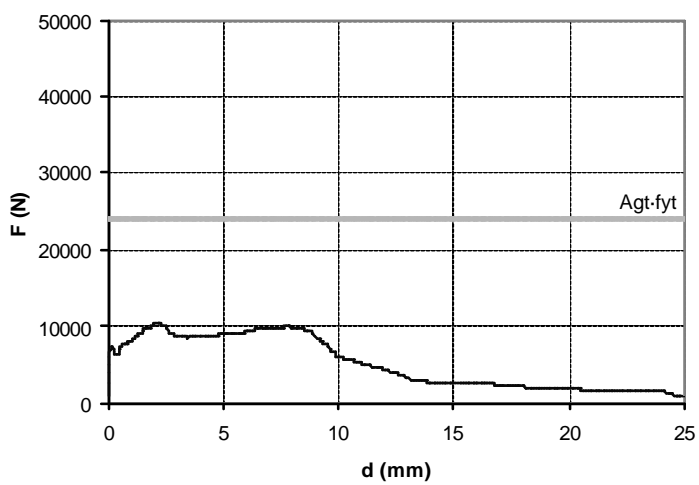

Fig. 11. F-d curve of a $T+B+T S$ joint. Specimen 0,85-1,5-8-1-S250.

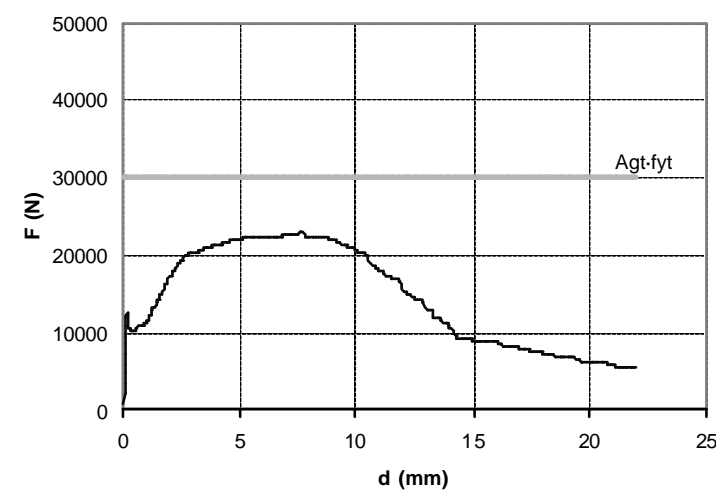

Fig. 13. F-d curve of a $T+B+T S$ joint. Specimen 1-1-8-2-S250-A.

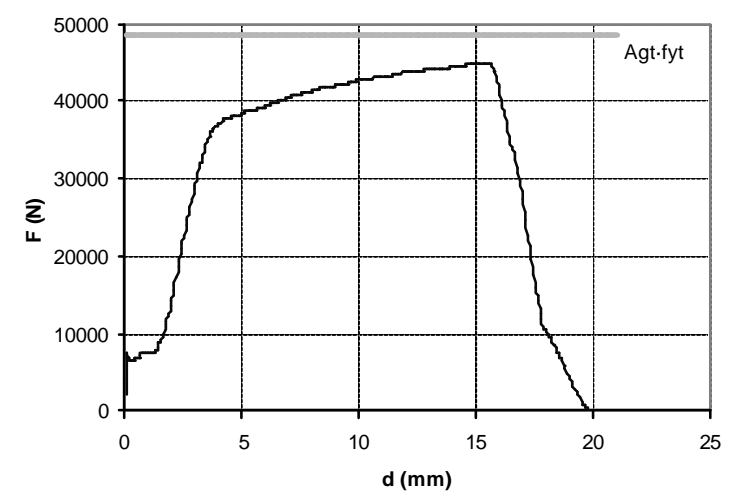

Fig. 10. F-d curve of a $T+B+N S F$ joint. Specimen 1,5-1,5-10-2-S250.

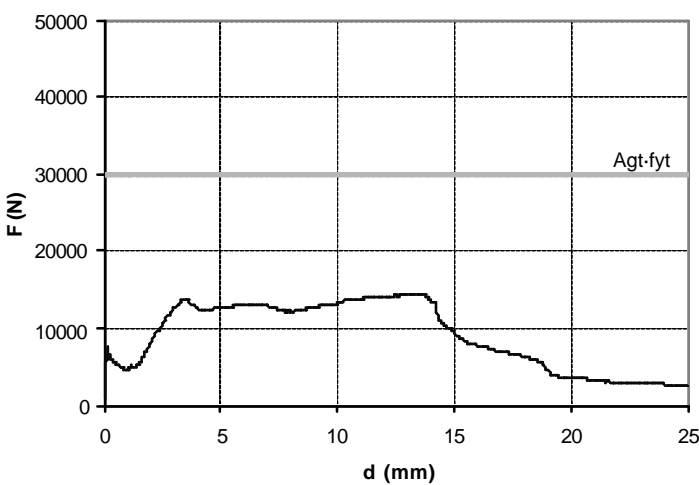

Fig. 12. F-d curve of a $T+B+T S$ joint. Specimen 1-1-10-1-S250-C.

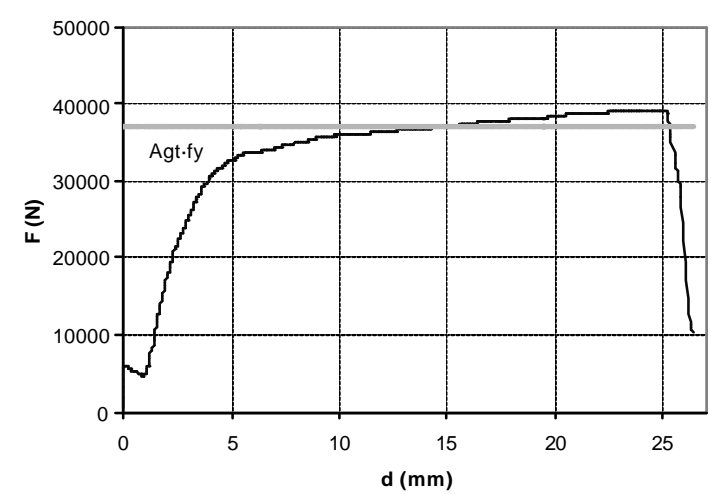

Fig. 14. F-d curve of a $T+B+N S F$ joint. Specimen 1-1-10-2-S350-A (W).

by a hardening branch with one or more load peaks. The maximum load is achieved just before the first drop Fig. 11) or, afterwards, in the hardening interval (Fig. 12).

When a $\mathrm{T}+\mathrm{B}+\mathrm{TS}$ joint connects two straps by means of two columns of bolts, the F-d curve may be different. See, for instance, the curve of Fig. 13, where neither the first drop nor the hardening branch are well defined. 
Table 3. Ductility ratios and stiffness.

$r_{d}$ : displacement ductility ratio, $r_{f}$ : force ductility ratio, $k_{1}$ : stiffness of the first linear branch, $k_{2}$ : stiffness of the second linear branch, $d_{u}$ : ultimate displacement.

\begin{tabular}{|c|c|c|c|c|c|}
\hline Connection & $r_{d}$ & $r_{f}$ & $\mathrm{k}_{1}$ & $\mathrm{k}_{2}$ & $\underset{(\mathrm{mm})}{\mathrm{d}_{\mathrm{u}}}$ \\
\hline $0,85-0,85-10-2-S 250$ & 18,9 & 0,95 & 75323 & - & 20,4 \\
\hline $0,85-1-10-2-S 250$ & 10,9 & 1,00 & 66268 & 6239 & 17,7 \\
\hline $0,85-1,5-10-2-S 250$ & 14,5 & 1,02 & 95235 & 8811 & 19,2 \\
\hline 1-1-10-2-S250-A & 7,0 & 0,94 & 75260 & 7538 & 14,3 \\
\hline $1-1-10-2-S 250-B$ & 9,9 & 0,94 & 80692 & 8612 & 19,4 \\
\hline $1-1-10-2-S 250-C$ & 7,2 & 0,96 & 78000 & 9174 & 15,4 \\
\hline 1-1-10-2-S250-D & 5,6 & 0,95 & 75965 & 8087 & 13,4 \\
\hline 1-1-10-2-S250-E(W) & 16,5 & 1,02 & 69000 & 9450 & 26,8 \\
\hline 1-1-10-2-S250-F(W) & 13,4 & 1,05 & 61031 & 8919 & 24,9 \\
\hline 1-1-10-2-S250-G & 6,5 & 0,94 & 74353 & 7549 & 15,7 \\
\hline $1-1,5-10-2-S 250$ & 6,6 & 1,00 & 85337 & 11271 & 14,9 \\
\hline $1,5-1,5-10-2-S 250$ & 6,0 & 0,92 & 121200 & 14890 & 15,5 \\
\hline $0,85-0,85-8-2-S 250$ & 8,9 & 0,86 & 67083 & - & 8,9 \\
\hline $0,85-1-8-2-S 250$ & 13,1 & 0,86 & 68744 & 3470 & 10,6 \\
\hline $0,85-1,5-8-2-S 250$ & 12,9 & 0,97 & 81365 & 5096 & 16,2 \\
\hline 1-1-8-2-S250-A & 3,9 & 0,76 & 83900 & 5883 & 7,7 \\
\hline 1-1-8-2-S250-B & 3,6 & 0,75 & 84000 & 6842 & 10,1 \\
\hline $1-1,5-8-2-S 250$ & 4,8 & 0,94 & 66700 & 9306 & 10,3 \\
\hline $1,5-1,5-8-2-S 250$ & 3,1 & 0,77 & 78520 & 10761 & 10,4 \\
\hline $0,85-0,85-10-1-S 250$ & 8,0 & 0,59 & 97228 & - & 11,1 \\
\hline $0,85-1-10-1-S 250$ & 4,6 & 0,54 & 64200 & 3592 & 9,0 \\
\hline $0,85-1,5-10-1-S 250$ & 4,7 & 0,52 & 54208 & 5206 & 8,4 \\
\hline $1-1-10-1-S 250-A$ & 4,0 & 0,51 & 76850 & 4427 & 10,2 \\
\hline 1-1-10-1-S250-B & 4,5 & 0,50 & 57454 & 4585 & 9,5 \\
\hline $1-1-10-1-S 250-C$ & 6,0 & 0,48 & 60836 & 4431 & 13,5 \\
\hline 1-1-10-1-S250-D & 4,0 & 0,51 & 60622 & 4147 & 9,5 \\
\hline 1-1-10-1-S250-E(W) & 6,1 & 0,58 & 76350 & 6600 & 9,7 \\
\hline 1-1-10-1-S250-F(W) & 5,6 & 0,60 & 64533 & 5201 & 8,5 \\
\hline $1-1-10-1-S 250-G$ & 3,0 & 0,50 & 66428 & 4061 & 10,2 \\
\hline $1-1,5-10-1-S 250$ & 2,6 & 0,47 & 63216 & 4396 & 6,6 \\
\hline $1,5-1,5-10-1-S 250$ & 4,4 & 0,53 & 83000 & 7901 & 8,9 \\
\hline $0,85-0,85-8-1-S 250$ & 6,5 & 0,52 & 57750 & 4993 & 8,4 \\
\hline $0,85-1-8-1-S 250$ & 7,4 & 0,42 & 60417 & 3490 & 8,5 \\
\hline $0,85-1,5-8-1-S 250$ & 4,7 & 0,43 & 65366 & 2164 & 8,1 \\
\hline 1-1-8-1-S250-A & 7,4 & 0,41 & 69388 & 3297 & 8,2 \\
\hline 1-1-8-1-S250-B & 2,6 & 0,40 & 47137 & 2834 & 7,4 \\
\hline $1-1,5-8-1-S 250$ & 4,9 & 0,44 & 68450 & 3466 & 8,7 \\
\hline 1,5-1,5-8-1-S250 & 3,0 & 0,45 & 100500 & 5134 & 8,4 \\
\hline 1-1-10-1-S350(W) & 2,4 & 0,53 & 61766 & 5978 & 8,1 \\
\hline $1,5-1,5-10-1-S 350(W)$ & 5,3 & 0,81 & 71550 & 9391 & 17,4 \\
\hline 1-1-10-2-S350-A(W) & 6,9 & 1,06 & 65937 & 9676 & 24,5 \\
\hline 1-1-10-2-S350-B(W) & 7 & 1,04 & 57000 & 9574 & 19,9 \\
\hline $1,5-1,5-10-2-S 350(W)$ & 8,4 & 1,06 & 82300 & 15752 & 20,0 \\
\hline
\end{tabular}




\subsection{Ductility and stiffness of the connections}

The ductility of the connections is studied by means of the displacement ductility ratio $r_{d}=d_{u} / d_{y}$, where $d_{u}$ is the displacement corresponding to the maximum load (or to the last load peak, in curves such as the one shown in Fig. 11), and $d_{y}$ is the displacement at yielding.

All the calculated $r_{d}$ ratios are above 2 , as shown in Table 3 , so the joints can be considered ductile. From Figs. 15 and 16, which depict the values of the ductility ratios and the values of displacement at failure, respectively, it can also be concluded that $\mathrm{T}+\mathrm{B}+\mathrm{NSF}$ joints are more ductile than $\mathrm{T}+\mathrm{B}+\mathrm{TS}$ joints.

In relation to ductility, it was also investigated whether the two types of $\mathrm{T}+\mathrm{B}+\mathrm{TS}$ failure mentioned in section 4.1 show different $r_{d}$ values. The conclusion of this study is that both modes of failure give similar ductility ratios and similar F-d curves.

Apart from the ductility ratios, the stiffness of the two initial elastic branches is included in Table 3, where $k_{1}$ and $k_{2}$ are the values measured before and after slipping, respectively.

The effect of different parameters on these stiffnesses has been investigated. It is possible to see that both $k_{1}$ and $k_{2}$ increase with the number of bolt columns. No other clear correlation between $k_{1}$ and other parameters can be found from

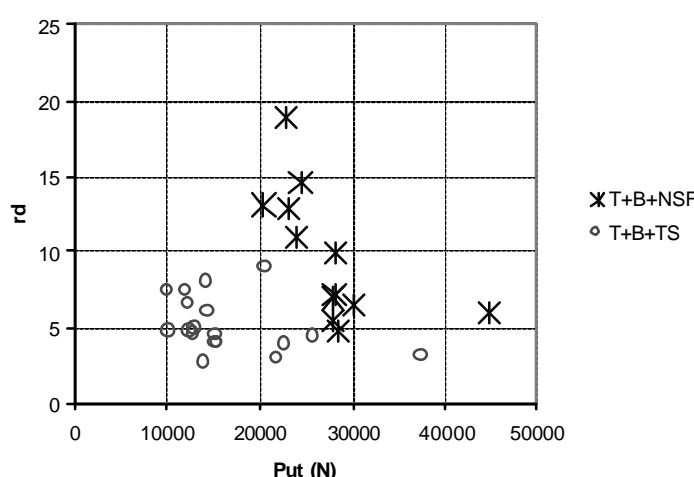

Fig. 15. Ratio $\mathrm{r}_{\mathrm{d}}=\mathrm{d}_{\mathrm{u}} / \mathrm{d}_{\mathrm{y}}$ vs ultimate load $\mathrm{P}_{\mathrm{ut}}$

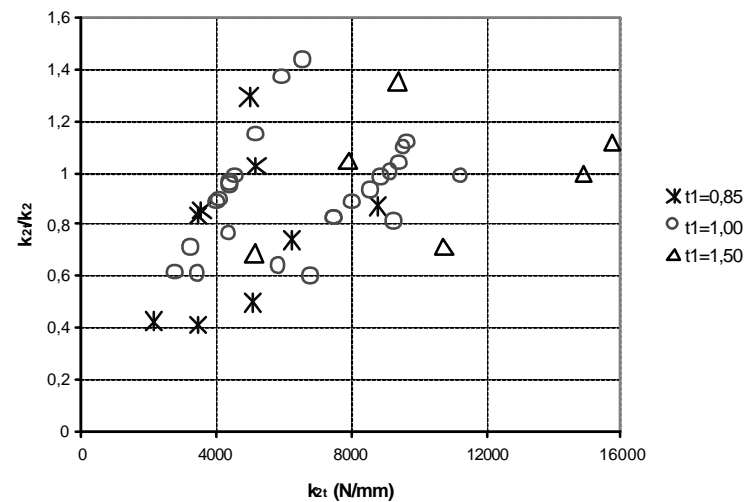

Fig. 17. $k_{2} / k_{2}$ values. $k_{2 t}$ calculated with (1).

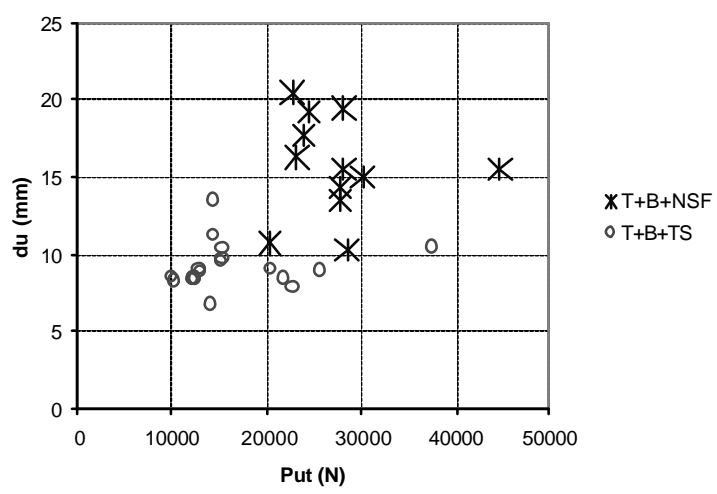

Fig. 16. Displacement $\mathrm{d}_{\mathrm{u}}$ vs ultimate load $\mathrm{P}_{\mathrm{ut}}$

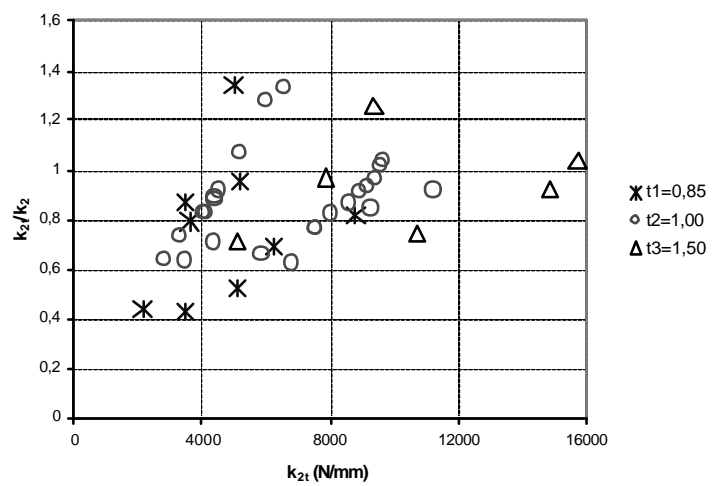

Fig. 18. $k_{2} / k_{2}$ values. $k_{2}$ calculated with (2). 
the results of the tests performed. On the contrary, it is verified that $k_{2}$ also depends on the thickness of the sheets and the diameter of the bolts. The higher the values of these parameters, the higher the stiffness.

Similar results are obtained in two other investigations on stiffness $9,12,13]$, which also propose formulas for the calculation of $\mathrm{k}_{2}$ :

$$
\begin{array}{ll}
k_{2}=\frac{10^{3}}{5 \cdot n \cdot\left(\frac{10}{t_{1}}+\frac{10}{t_{2}}-2\right)} & \text { from }[9,12] \\
k_{2}=6,8 \cdot \frac{\sqrt{d}}{\left(\frac{5}{t_{1}}+\frac{5}{t_{2}}-1\right)} & \text { from }[13]
\end{array}
$$

where:

d: diameter of the bolt,

$t_{1}, t_{2}$ : measured thickness of the straps (from Table 2)

$\mathrm{n}=5$ for joints in tension where the position of the shear plane is in the threaded part of the bolt shaft (see [12]).

These formulas have been applied here to predict the stiffness of the connections tested. The values obtained with both equations are similar, and many of them above the experimental results (Figs. 17 and 18):

$$
\begin{aligned}
& \text { Equation (1): Mean value of } k_{2} / k_{2}: \gamma_{k 2} \text { mean }=0,90 \text {, } \\
& \text { Standard deviation of } \mathrm{k}_{2} / \mathrm{k}_{2}: \mathrm{s}_{\gamma}=0,24 \text {. }
\end{aligned}
$$

Equation (2): Mean value of $k_{2} / k_{2}: \gamma_{k_{2}}$ mean $=0,86$

Standard deviation of $k_{2 t} / k_{2}: s_{\gamma}=0,21$,

where:

$\mathrm{k}_{2 \mathrm{t}}$ : experimental stiffness,

$\mathrm{k}_{2}$ : calculated stiffness.

It should be noted that equation (1) was defined to overestimate the value of $k_{2}$ [12], and that the thickness of the straps tested are out of the range of validity of equation (2) [13].

No formula has been found in the literature to predict the value of $k_{1}$. In fact, in [12] it is stated that the stiffness of the connection only depends on $k_{2}$, because slippage always occurs before the service life of the structure. For this reason, $k_{1}$ is not considered relevant. An F-d model is even proposed in [12], where $k_{2}$ is used for the stiffness before and after slipping. However, it should be noticed that $k_{1}$ is considerably higher than $k_{2}$ (Table 3 ), and that, if a connection is designed without slipping [12], $\mathrm{k}_{1}$ becomes relevant. 


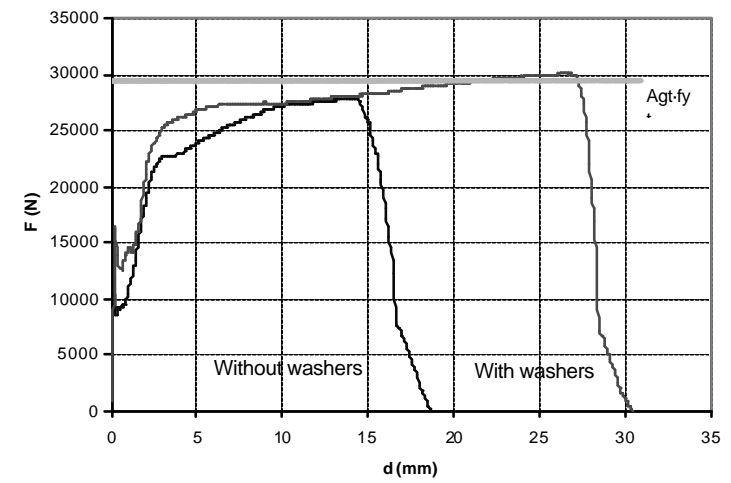

Fig. 19. F-d curve of a $T+B+N S F$ joint. Specimen 1-1-10-2-S250.

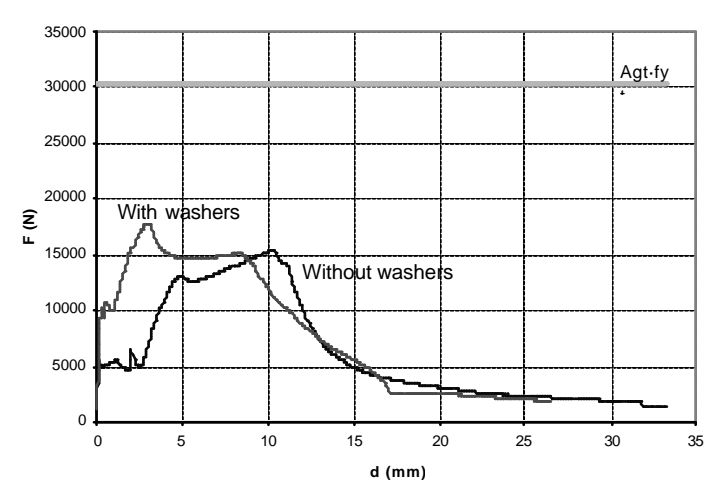

Fig. 20. F-d curve of a $T+B+T S$ joint. Specimen 1-1-10-1-S250.

\subsection{The effect of washers on the strength and behaviour of joints}

Joints 1-1-10-2-S250 and 1-1-10-1-S250 were tested with and without washers. Comparing the results of the tests, it can be seen that washers increase the strength of connections. The resistance of joint 1-1-10-2-S250, which fails T-BTS, is $8.6 \%$ higher when washers are used. The increase in strength of joint 11-10-S250, which fails $\mathrm{T}+\mathrm{B}+\mathrm{NSF}$, is even higher, close to $17 \%$.

Washers also increase the ductility of the $\mathrm{T}+\mathrm{B}+\mathrm{NSF}$ joint. This can be clearly seen in Fig. 19, where the F-d curves of the joint with and without washers are compared. The corresponding values of displacement ratio also allow to detect this gain in ductility: $r_{d}=7.40$ and $r_{d w}=14.97$ (mean values).

On the contrary, washers almost do not change the ductility of joint 1-1-10-1$\mathrm{S} 250$, that fails $\mathrm{T}+\mathrm{B}+\mathrm{TS}$. Its displacement ratio only increases from $r_{d}=4.62$ to $r_{d w}=5.83$. Fig. 20 also shows that the F-d curves are not considerably affected. It can only be observed an increase in ultimate load, but not an increase in ultimate displacement.

However, washers modify the behaviour of $T+B+T S$ joints in one sense. They change the mode of failure of those joints where the tears provoked by bearing originate near the center of the bolt holes. When washers are used, these joints fail in pure bearing, showing tears initiated at the edge of the zone affected by bearing (see Figs. 21 and 22).

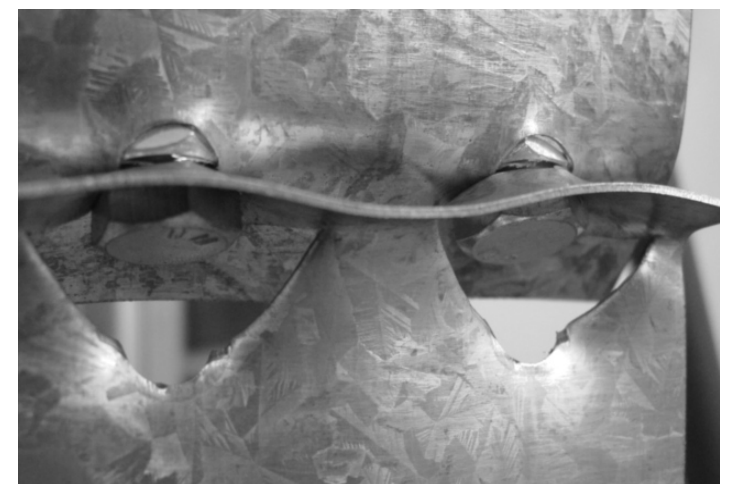

Fig. 21. $T+B+T S$ failure of specimen 1-1-10-1-S250-A, without washers.

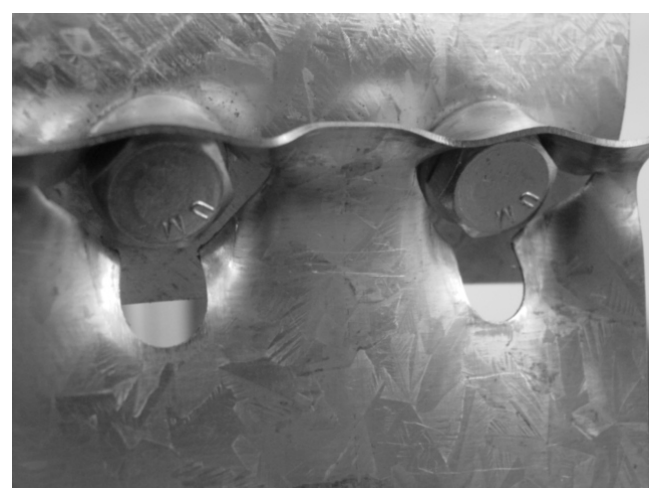

Fig. 22. $T+B+T S$ failure of specimen 1-1-10-1-S250-F, with washers. 


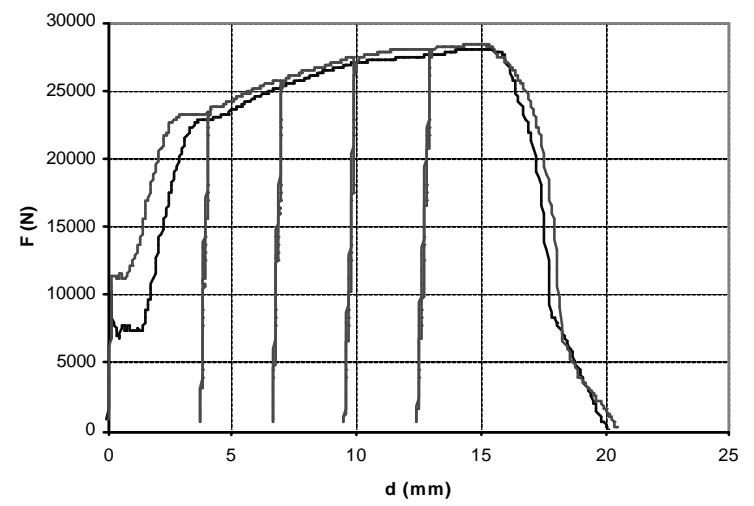

Fig. 23. F-d curve of a load-unload test. Specimen 1-1-10-2-S250.

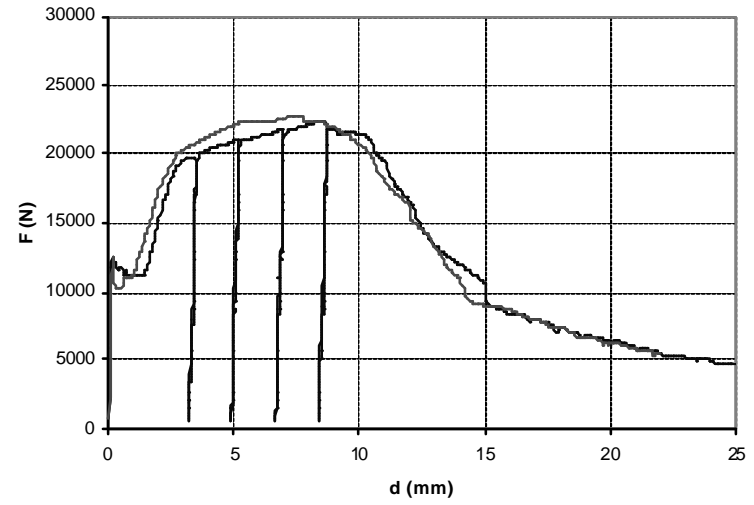

Fig. 24. F-d curve of a load-unload test. Specimen 1-1-8-2-S250.

\section{Results of load-unload tensile tests}

As it occurred in screw connections [2], the unloading of the specimens does not change the results of the tests. The F-d curves, the modes of failure and the ultimate loads are similar to those of the monotonic tensile tests. For the sake of comparison, Figs. 23 and 24 show, plotted in the same graph, curves of monotonic and load-unload tests.

It can also be seen that the unloading paths are similar to the reloading paths, and that no stiffness degradation occurs.

\section{Joint design for $\mathrm{X}$-braced dissipative frames}

A force ductility ratio is defined as $r_{f}=P_{u t} /\left(A_{g t} \cdot f_{y t}\right)$, where $P_{u t}$ is the experimental ultimate load of the joint, and $\left(A_{g t} \cdot f_{y t}\right)$ is the yielding load of the strap, calculated from the measured gross cross section area, $A_{g t}=a_{t} \cdot t_{t}($ Table 2), and the measured yield stress of the steel, $f_{y t}$ (Table 1). This ratio allows to know if a joint is suitable for seismic design [2]. Joints with ratios higher than 1 have good seismic behaviour, because they fail once the strap has already yielded and, as a consequence, the dissipative action can develop.

Fig. 25 shows the $r_{f}$ values calculated for all the specimens connected without washers. The ratios of the T+B+TS joints are rather low, ranging from 0,4 to about 0,8 . Ratios of $T+B+N S F$ joints are better, but most of them are also below 1. Therefore, it can be concluded from these results that, although bolted connections are ductile, as discussed in section 4.3, they are not suitable for seismic design. They do not allow the dissipative action of diagonal straps in $x-$ braced frames.

When washers are used, the strength of $\mathrm{T}+\mathrm{B}+\mathrm{TS}$ connections increases, but their ductility does not change considerably (section 4.4). On the contrary, the effect of washers on T+B+NSF joints is more significant (Fig. 27). They exhibit longer hardening branches and failure loads higher than the yielding loads of the straps. This results in good $r_{f}$ values $\left(r_{f}>1\right)$, as shown in Table 3. 


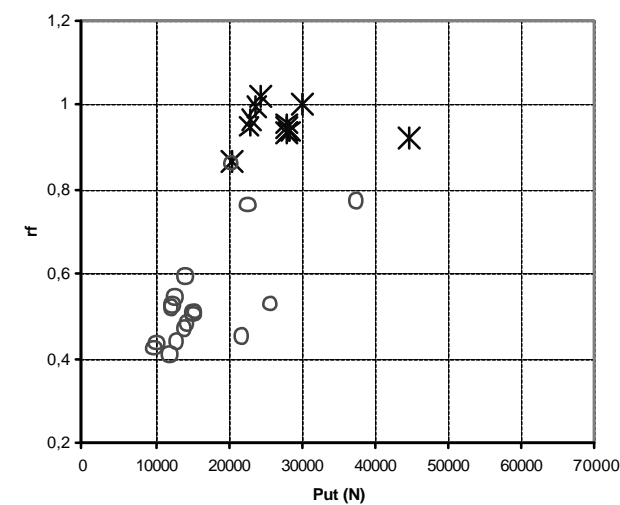

Fig. 25. Strength ductility ratio vs ultimate load.

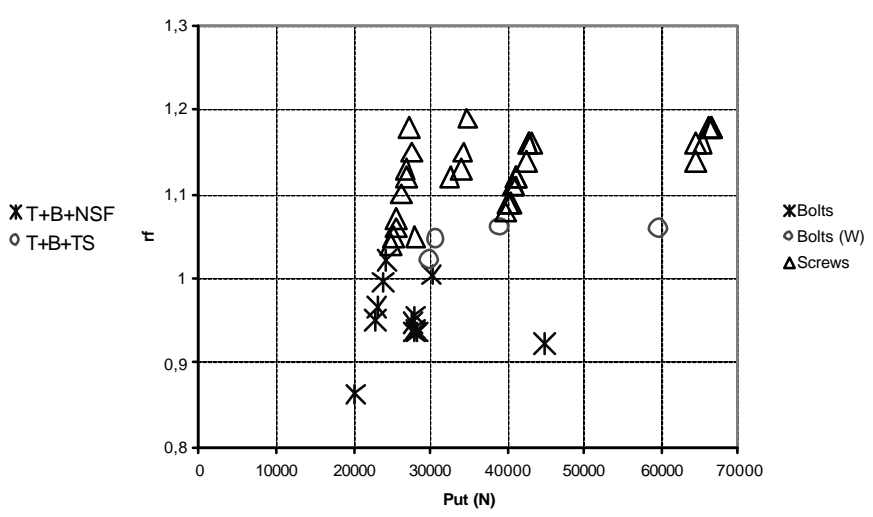

Fig. 26. Strength ductility ratio vs ultimate load for screw and bolt NSF joints.

The F-d curves included in this paper are plotted together with the calculated yielding load of the straps, so that it can be directly evaluated whether a joint is suitable for seismic design. It should be noticed that all the F-d curves of $\mathrm{T}+\mathrm{B}+\mathrm{NSF}$ joints with washers cross the line of yielding load; but almost none of the joints without washers cross it. See Figs. 14 and 19 of specimens 1-1-10-2S350-A and 1-1-10-2-S250, respectively.

The force ductility ratios of T+B+NSF bolt joints are compared in Fig. 26 to the ratios of T+NSF joints obtained in the previous investigation on screws [2]. This figure clearly evidences that, from the seismic point of view, screw joints are better than bolt joints. Notice that all the ratios of the screw connections are above 1. The use of washers in T+B+NSF bolted joints improve their ratios, good values are obtained $\left(r_{f}>1\right)$, but it is important to point out that these values are still low compared to the ratios of screw connections.

\section{Strength of bolted connections}

In this section, the connection maximum load carrying capacities obtained in the tests are compared to those that result from design calculations.

The Eurocode 3 Part 1.3 is applied to predict the strength of specimens. According to this code, there are three possible modes of failure when loading a joint in shear: bearing (includes end-tearing), net-section failure and shear failure of the screws. This last mode is not considered in this paper, because it is not observed in the tests.

The strength of the connections is calculated as follows:

-Bearing resistance:

$$
P_{b, R d}=2,5 \cdot \alpha_{b} \cdot k_{t} \cdot f_{u} \cdot d \cdot t / \gamma_{M 2}
$$

where:

$$
\alpha_{b} \text { is the smallest of } 1,0 \text { or } e_{1} /(3 \cdot d) \text {; }
$$


$\mathrm{e}_{1}$ : end distance from the centre of the bolt to the adjacent end of the connected part, in the direction of load transfer;

$\mathrm{d}$ : nominal diameter of the bolt;

$k_{t}=(0,8 \cdot t+1,5) / 2,5$ for $0,75 m m \leq t \leq 1,25 m m, k_{t}=1,0$ for $t>1,25 m$;

$\mathrm{t}$ : thickness of the thinner connected strap;

$f_{u}$ : ultimate tensile strength of the strap ( $f_{u t}$ in Table 1$)$;

$\gamma_{\mathrm{M} 2}$ : material partial factor.

-Net-section resistance:

$$
P_{n, R d}=\left(1+3 \cdot r \cdot\left(d_{0} / u-0,3\right)\right) \cdot A_{n} \cdot f_{u} / \gamma_{M 2} \text { but } P_{n, R d} \leq A_{n} \cdot f_{u} / \gamma_{M 2}
$$

where:

$r=$ (number of bolts at the cross-section) / (total number of bolts in the connection);

$\mathrm{d}_{0}$ : nominal diameter of the hole;

$\mathrm{u}=2 \cdot \mathrm{e}_{2}$ but $\mathrm{u}=\mathrm{p}_{2}$;

$\mathrm{e}_{2}$ : edge distance from the centre of the bolt to the adjacent edge of the connected part, in the direction perpendicular to the direction of load transfer;

$\mathrm{p}_{2}$ : spacing centre-to-centre of bolts in the direction perpendicular to the direction of load transfer;

$A_{n}$ : net cross-sectional area of the strap;

$f_{u}$ : ultimate tensile strength of the strap ( $f_{u t}$ in Table 1);

$\gamma_{\mathrm{M} 2}:$ material partial factor.

The strength calculations are carried out taking $\gamma_{\mathrm{M} 2}$ equal to 1 and using the core thickness of the strap: $t_{\text {cor }}=t-t_{\text {coating }}=t-0,04 \mathrm{~mm}$, where $t_{t}$ is the measured thickness of the thinner steel sheet (Table 2 ).

The results obtained applying the above formulas can be observed in Table 4, where the third and fourth columns include the net-section and the bearing resistance, respectively. The mode of failure of the joints is predicted on the basis of these calculated strengths. The critical mode is the one that gives the lowest ultimate load. In view of the values of the mentioned columns and the sixth column of Table 2, it can be concluded that good predictions of the failure mode are obtained by means of equations (3) and (4). The Eurocode 3 equations fail in only four specimens, most of which show calculated bearing strengths similar to calculated net-section strengths (see values of specimens 0,85-0,85-8-2-S250, 1-1-8-2-S250-A and 1-1-8-2-S250-B).

\subsection{Connections failing $\mathrm{T}+\mathrm{B}+\mathrm{NSF}$}

The net-section failure equation (4) gives acceptable predictions of the $\mathrm{T}+\mathrm{B}+\mathrm{NSF}$ failure load, although they are slightly conservative. The $\mathrm{P}_{\mathrm{u}} / \mathrm{P}_{\mathrm{n}, \mathrm{Rd}}$ ratios of Table 4 and Fig. 27 show the accuracy of this formula: 
Table 4. Calculated strengths and strength ratios.

$\mathrm{P}_{\mathrm{u} 3 \mathrm{~mm}}$ : load at $3 \mathrm{~mm}$ displacement, $\mathrm{P}_{\mathrm{n}, \mathrm{Rd}}$ : calculated net-section resistance, $\mathrm{P}_{\mathrm{b}, \mathrm{Rd}}$ : calculated bearing resistance, Put: measured ultimate load,.

\begin{tabular}{|c|c|c|c|c|c|c|}
\hline Connection & $\begin{array}{c}P_{\mathrm{u} 3 \mathrm{~mm}} \\
(\mathrm{~N})\end{array}$ & $\begin{array}{l}P_{n, R d} \\
(N)\end{array}$ & $\begin{array}{c}P_{b, R d} \\
(N)\end{array}$ & $\frac{P_{u t}}{P_{n, R d}}$ & $\frac{P_{u t}}{P_{b, R d}}$ & $\frac{\mathrm{P}_{\mathrm{u} 3 \mathrm{~mm}}}{\mathrm{P}_{\mathrm{b}, \mathrm{Rd}}}$ \\
\hline $0,85-0,85-10-2-S 250$ & - & 19889,3 & 20981,5 & 1,14 & - & - \\
\hline $0,85-1-10-2-S 250$ & - & 19899,5 & 20981,5 & 1,20 & - & - \\
\hline $0,85-1,5-10-2-S 250$ & - & 19886,8 & 20981,5 & 1,23 & - & - \\
\hline $1-1-10-2-S 250-A$ & - & 26544,5 & 29322,0 & 1,05 & - & - \\
\hline $1-1-10-2-S 250-B$ & - & 26692,1 & 29724,9 & 1,06 & - & - \\
\hline 1-1-10-2-S250-C & - & 26152,8 & 28921,1 & 1,07 & - & - \\
\hline 1-1-10-2-S250-D & - & 26149,5 & 28921,1 & 1,06 & - & - \\
\hline 1-1-10-2-S250-E (W) & - & 26203,2 & 28921,1 & 1,15 & - & - \\
\hline 1-1-10-2-S250-F (W) & - & 26173,0 & 28921,1 & 1,17 & - & - \\
\hline $1-1-10-2-S 250-G$ & - & 26412,3 & 29322,0 & 1,07 & - & - \\
\hline $1-1,5-10-2-S 250$ & - & 26705,8 & 29724,9 & 1,13 & - & - \\
\hline $1,5-1,5-10-2-S 250$ & - & 41057,2 & 49852,5 & 1,09 & - & - \\
\hline $0,85-0,85-8-2-S 250$ & 17801,3 & 19490,9 & 19764,6 & - & 1,04 & 0,90 \\
\hline $0,85-1-8-2-S 250$ & - & 19256,5 & 19482,2 & 1,06 & - & - \\
\hline $0,85-1,5-8-2-S 250$ & - & 19490,9 & 19789,8 & 1,19 & - & - \\
\hline 1-1-8-2-S250-A & 21174,7 & 26157,9 & 28143,6 & - & 0,81 & 0,75 \\
\hline 1-1-8-2-S250-B & 20442,1 & 26157,9 & 28072,2 & - & 0,80 & 0,73 \\
\hline $1-1,5-8-2-S 250$ & 34301,5 & 26460,8 & 28454,8 & 1,07 & - & - \\
\hline $1,5-1,5-8-2-S 250$ & - & 40468,1 & 47328,2 & - & 0,79 & 0,72 \\
\hline $0,85-0,85-10-1-S 250$ & 10672,5 & 17377,2 & 10654,8 & - & 1,35 & 1,00 \\
\hline $0,85-1-10-1-S 250$ & 9707,2 & 17177,1 & 10490,8 & - & 1,23 & 0,93 \\
\hline $0,85-1,5-10-1-S 250$ & 9590,7 & 17172,7 & 10490,8 & - & 1,19 & 0,91 \\
\hline 1-1-10-1-S250-A & 12555,7 & 23291,1 & 15065,0 & - & 1,02 & 0,83 \\
\hline 1-1-10-1-S250-B & 12577,2 & 23297,0 & 15065,0 & - & 1,01 & 0,83 \\
\hline 1-1-10-1-S250-C & 12452,3 & 23052,2 & 14862,5 & - & 0,97 & 0,84 \\
\hline 1-1-10-1-S250-D & 13559,8 & 23291,1 & 15065,0 & - & 1,02 & 0,90 \\
\hline 1-1-10-1-S250-E (W) & 16873,3 & 23049,3 & 14862,5 & - & 1,18 & 1,14 \\
\hline 1-1-10-1-S250-F (W) & 15762,0 & 22819,4 & 14661,0 & - & 1,22 & 1,08 \\
\hline 1-1-10-1-S250-G & 12516,6 & 22825,2 & 14661,0 & - & 1,03 & 0,85 \\
\hline $1-1,5-10-1-S 250$ & 12598,8 & 23306,0 & 15065,0 & - & 0,94 & 0,84 \\
\hline $1,5-1,5-10-1-S 250$ & 23014,9 & 35917,4 & 25252,1 & - & 1,02 & 0,91 \\
\hline $0,85-0,85-8-1-S 250$ & 10443,7 & 15201,3 & 9920,1 & - & 1,25 & 1,05 \\
\hline $0,85-1-8-1-S 250$ & 7561,7 & 15249,5 & 9882,3 & - & 1,02 & 0,77 \\
\hline $0,85-1,5-8-1-S 250$ & 8530,6 & 15234,7 & 9882,3 & - & 1,05 & 0,86 \\
\hline 1-1-8-1-S250-A & 9755,0 & 20433,3 & 14036,1 & - & 0,87 & 0,69 \\
\hline 1-1-8-1-S250-B & 11478,3 & 20418,4 & 14018,3 & - & 0,87 & 0,82 \\
\hline 1-1,5-8-1-S250 & 11159,4 & 20393,5 & 14000,5 & - & 0,94 & 0,80 \\
\hline $1,5-1,5-8-1-S 250$ & 17817,6 & 31398,9 & 23480,5 & - & 0,93 & 0,76 \\
\hline 1-1-10-1-S350 (W) & 17192,7 & 28994,6 & 18346,3 & - & 1,07 & 0,94 \\
\hline $1,5-1,5-10-1-S 350(\mathrm{~W})$ & 27449,1 & 44394,4 & 31140,0 & - & 1,46 & 0,88 \\
\hline 1-1-10-2-S350-A (W) & - & 33585,6 & 36692,6 & 1,16 & - & - \\
\hline 1-1-10-2-S350-B (W) & - & 33589,9 & 36692,6 & 1,05 & - & - \\
\hline 1,5-1,5-10-2-S350 (W) & - & 51986,2 & 62712,5 & 1,15 & - & - \\
\hline
\end{tabular}




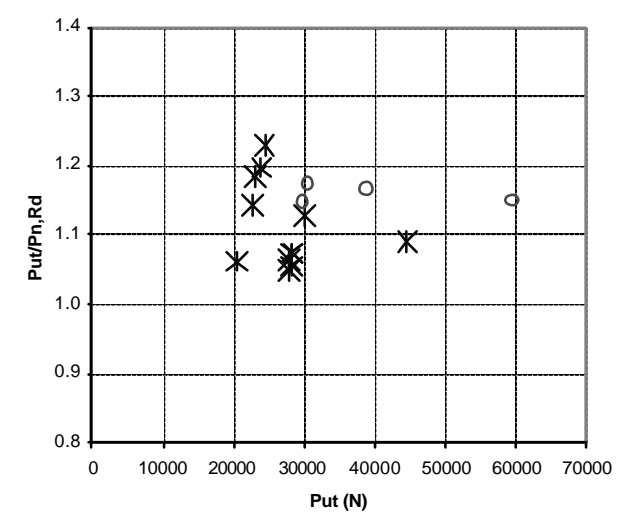

Fig. 27. Ratio $\mathrm{P}_{\mathrm{ut}} / \mathrm{P}_{\mathrm{n}, \mathrm{Rd}}$, for $T+B+N S F$ joints. $\mathrm{P}_{\mathrm{n}, \mathrm{Rd}}$ with reduction factor.

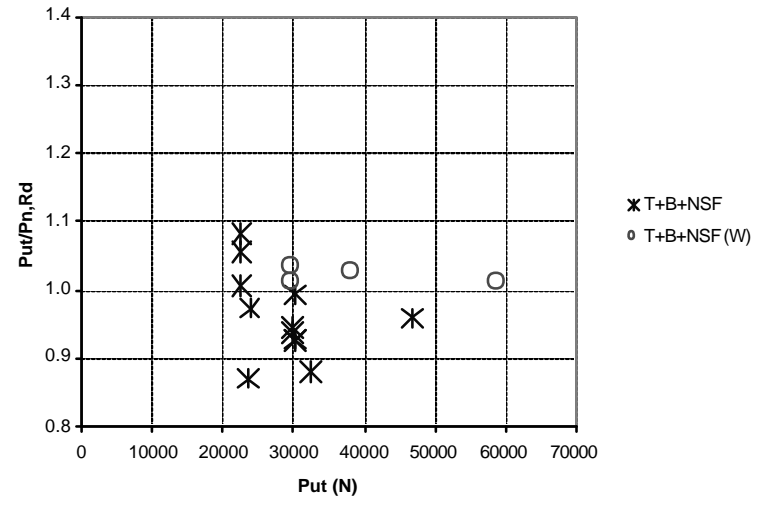

Fig. 28. Ratio $\mathrm{P}_{\mathrm{ut}} / \mathrm{P}_{\mathrm{b}, \mathrm{Rd}}$, for $T+B+T S$ joints. $\mathrm{P}_{\mathrm{n}, \mathrm{Rd}}$ without reduction factor.

Mean value of $P_{u t} / P_{n, R d}: \gamma_{u}$ mean $=1,14$

Standard deviation of $P_{u t} / P_{n, R d}: s_{\gamma}=0,05$.

Some investigations [11,14-16] claim that equation (4) is too conservative, and that the NSF ultimate load can be determined without any reduction factor:

$$
P_{n, R d}=A_{n} \cdot f_{u} / \gamma_{M 2}
$$

This may be true when straps are connected with washers, as in the mentioned works. In fact, Fig. 28 shows that predictions are better when the reduction factor is not applied to connections with washers. However, when equation (5) is applied to joints without washers, strengths are overestimated. See in Fig. 28 the $\mathrm{Put}_{\mathrm{ut}} / \mathrm{P}_{\mathrm{n}, \mathrm{Rd}}$ ratios obtained here for the joints tested without washers. The mean value is:

Mean value of $P_{\mathrm{ut}} / \mathrm{P}_{\mathrm{n}, \mathrm{Rd}}: \gamma_{\mathrm{u} \text { mean }}=0,96$

Standard deviation of $\mathrm{P}_{\mathrm{ut}} / \mathrm{P}_{\mathrm{n}, \mathrm{Rd}}: \mathrm{s}_{\gamma}=0,06$

\subsection{Connections failing $\mathrm{T}+\mathrm{B}+\mathrm{TS}$}

The Eurocode 3 strengths obtained for the bearing mode of failure are not as acceptable as the strengths obtained for the net-section mode (Table 4):

$$
\gamma_{u \text { mean }}=1,05 ; s_{\gamma}=0,16
$$

The mean value of the $P_{u t} / P_{b}$,Rd ratio is good, but the dispersion is too high (see also Fig. 29). There can be seen values of strength clearly underestimated for joints with washers and joints with $10 \mathrm{~mm} \Phi$ bolts. The worst results, however, are those obtained for some $8 \mathrm{~mm} \Phi$ joints, whose bearing strength is overestimated:

joints with washers: $\gamma_{u}$ mean $=1,23 ; s_{\gamma}=0,16$,

$10 \mathrm{~mm} \Phi$ joints: $\gamma_{\mathrm{u} \text { mean }}=1,12 ; \mathrm{s}_{\gamma}=0,15$,

$8 \mathrm{~mm} \Phi$ joints: $\gamma_{\mathrm{u} \text { mean }}=0,97 ; \mathrm{s}_{\gamma}=0,14$. 
In relation to this, it was noticed that some of $8 \mathrm{~mm}$ diameter joints showed a bearing failure mode slightly different from the mode of failure of $10 \mathrm{~mm}$ diameter joints. A clear tearing out failure was observed when $10 \mathrm{~mm} \Phi$ bolts were used (Fig. 30), while for $8 \mathrm{~mm} \Phi$ bolts the tearing was mixed with a sort of punching or pull-out phenomenon similar to that of screwed connections (see Figs. 31 and 32).

It is also interesting to discuss Fig. 33, uhere $P_{u t} / P_{n, R d}$ ratios of joints without washers are plotted against $d / t$ ratios. This figure shows that the higher the $d / t$ ratio, the more conservative the strength prediction. In view of this result, it is believed that one way of improving the predictions of equation (3) may be by using a gradated bearing factor, which would depend on $\mathrm{d} / \mathrm{t}$. Gradated bearing factors have been succesfully applied in other investigations [11,14-18].

Finally, it is pointed out that the Eurocode 3 bearing formula was established on the basis experimental load values that corresponded to $3 \mathrm{~mm}$ of displacement [19]. For this reason, the results of equation $(3)\left(P_{b}, R d\right)$ are also compared to the $3 \mathrm{~mm}$ loads $\left(P_{\text {uzmm }}\right)$. As it can be seen in Fig. 34 , the $P_{\text {u3mm }}$ load of the joints tested are lower than the predicted values.

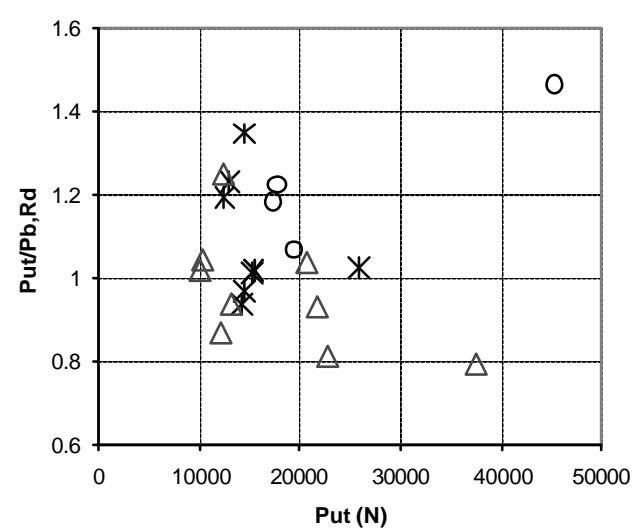

Fig. 29. Ratio $\mathrm{P}_{\mathrm{ut}} / \mathrm{P}_{\mathrm{n}, \mathrm{Rd}}$, for $T+B+T S$ joints.

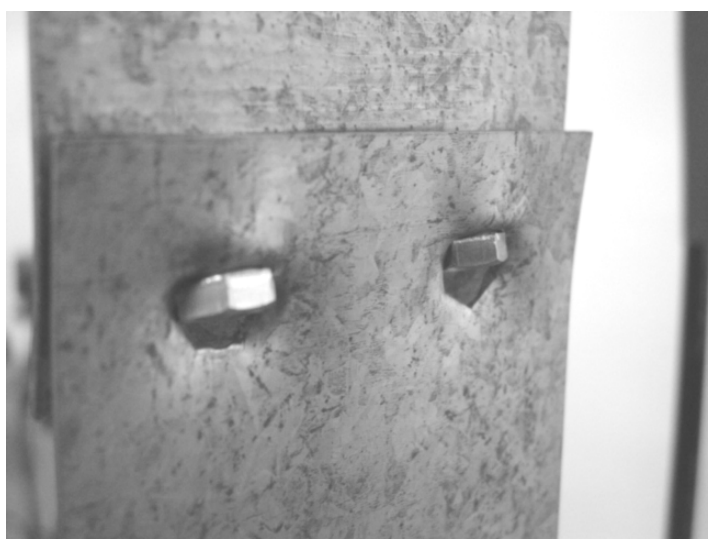

Fig. 31. Failure of specimen 1,5-1,5-8-1-S250.

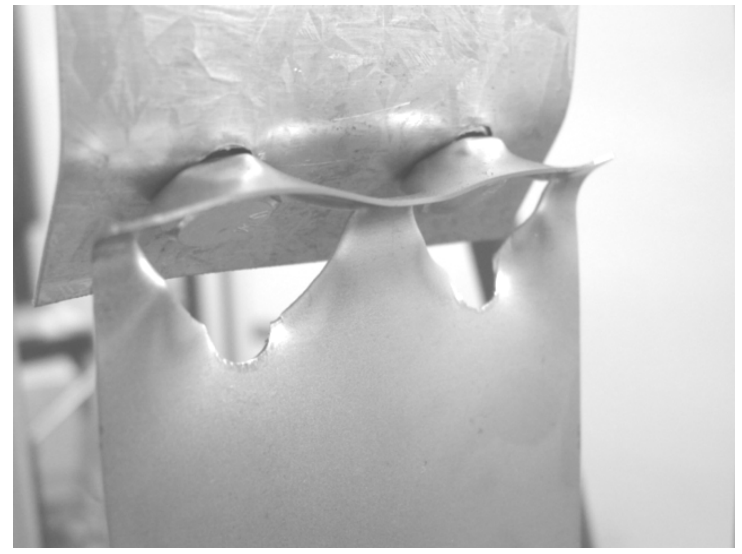

Fig. 30. Bearing failure in specimen 0,85-1-10-1-S250.

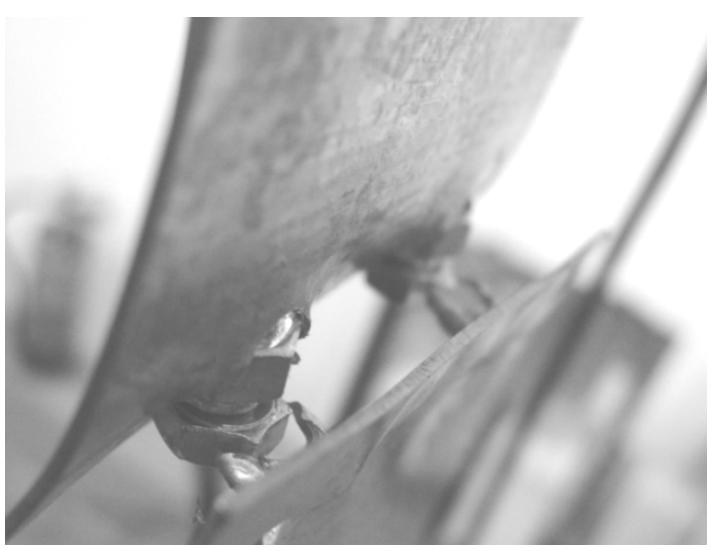

Fig. 32. Failure of specimen 1,5-1,5-8-1-250. 


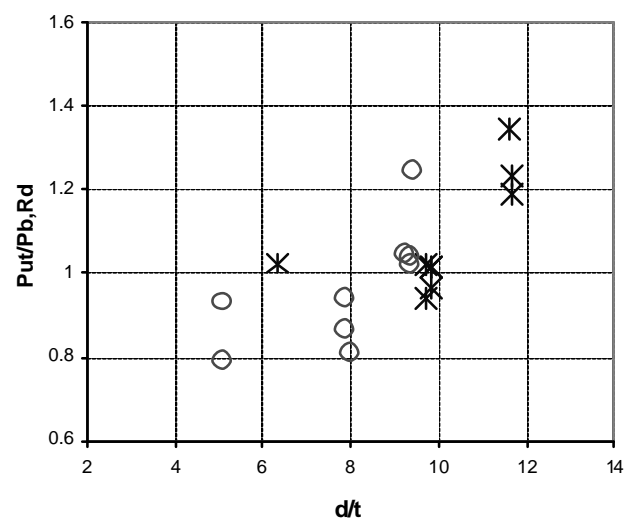

Fig. 33. Ratio $\mathrm{P}_{\mathrm{ut}} / \mathrm{P}_{\mathrm{n}, \mathrm{Rd}}$, for $T+B+N S F$ joints.

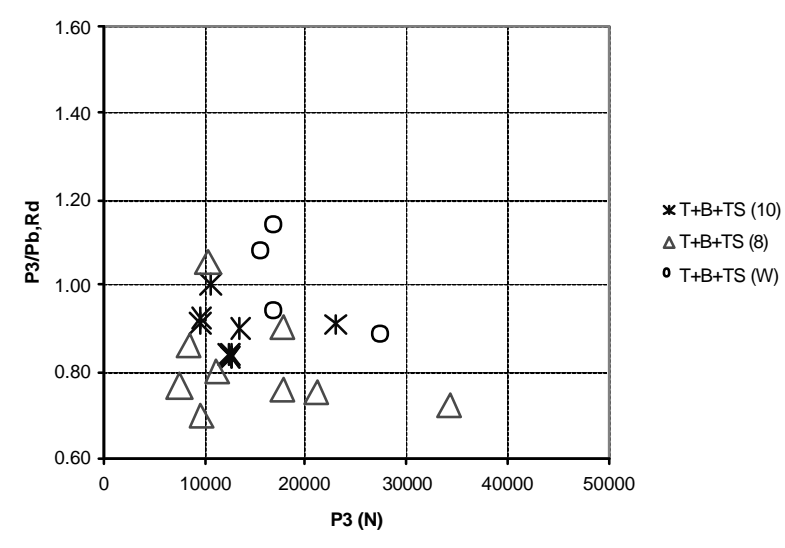

Fig. 34 Ratio $\mathrm{P}_{\mathrm{u} 3 \mathrm{~mm}} / \mathrm{P}_{\mathrm{b}, \mathrm{Rd}}$, for $T+B+T S$ joints.

It should be noted that for many of the joints the $P_{u 3 m m}$ load is not the maximum load measured in the test. Maximum loads are usually achieved in the range of $6 \mathrm{~mm}$ to $11 \mathrm{~mm}$. The same happened in the tests of screw connections.

\section{Recommendations}

Recommendations are given in this section for the design of bolted joints between straps of cold formed steel structures. These recommendations, which are mainly related to the geometric layout of the connection, can be classified in two groups:

a) Recommendations for increasing the ductility of the joint

b) Recommendations for improving the seismic performance of the joint.

a) Recommendations for increasing the ductility of the joint

The experimental tests prove that the $\mathrm{T}+\mathrm{B}+\mathrm{NSF}$ mode of failure is rather more ductile than $\mathrm{T}+\mathrm{B}+\mathrm{PO}$ mode. Therefore, it is recommended to design joints that fail NSF, i.e., to design joints whose bearing strength is higher than the netsection strength $\left(F_{b, R d}>F_{n, R d}\right)$.

From the design point of view and according to the Eurocode 3 calculation formulas:

1. The bearing strength does not increase linearly with the thickness of the sheet [12]. For this reason, the Eurocode 3 bearing equation (3) includes the factor $k_{t}$, which gives values below 1 when the thickness of the sheet is lower than $1.25 \mathrm{~mm}$. Therefore, if a high value of $F_{b, R d}$ is wanted, so that $F_{b, R d}>F_{n, R d}$, sheet thickness above $1,25 \mathrm{~mm}$ are recommended.

2. The bearing formula was defined for the bearing failure and also for the end-tearing failure. The effect of tearing on strength is considered by means of the $\alpha_{b}$ factor in equation (3) [12]. To avoid values of $\alpha_{b}$ below 1 , 
bolts should be placed far enough from the end edge of the strap $\left(e_{1}>3 \mathrm{~d}\right.$ according to Eurocode 3 ). This will also increase $F_{b, R d}$ with respect to $F_{n, R d \text {. }}$

A ductile failure $\left(F_{b, R d}>F_{n, R d}\right)$ does not guarantee that the joint will be suitable for seismic design. Other requirements should be accomplished, as it is explained in the following point (see also section 6).

b) Recommendations for improving the seismic performance of the joint.

The objective is to design joints whose strength is higher than the yielding load of the gross cross-section $\left(F_{n, R d}>A_{g t} \cdot f_{y}\right)$, i.e., joints with $r_{f}>1$, so that the dissipative action of the straps can develop.

In section 6, it has been shown that bolted connections without washers do not satisfy this condition. On the one hand, bolt joints failing $T+B+T S$ exhibit very low values of $r_{f}$ ratio and, consequently, they will never be suitable for seismic design. On the other hand, $\mathrm{T}+\mathrm{B}+\mathrm{NSF}$ joints show higher $\mathrm{i}_{\mathrm{f}}$ ratios, but most of them are lower than 1 . The main problem with these joints is that the diameter of the bolts is high, and it is not easy to keep the net-section area large enough to allow the dissipative yielding of the straps.

However, the behaviour of the $\mathrm{T}+\mathrm{B}+\mathrm{NSF}$ connections improves when washers are used, their $r_{f}$ ratios become higher than 1 . This is observed for all the joints tested with washers. Therefore, the main recommendation is that bolt joints should be used with washers and designed to fail NSF.

Other recommendations may be given in order to increase the $r_{f}$ values:

1. Choose the steel with the highest $f_{u} / f_{y}$ ratio, which will directly increase the $F_{n, R d} / A_{g} \cdot f_{y}$ ratio.

2. Use only a row of bolts, which increases the net-section area.

3. Drill the minimum feasible bolt diameter, so that the maximum netsection area is available.

4. Enlarge the width of the straps in the perforated section to avoid the net section failure.

5. Place the bolts so that $e_{2}>1,66 d$, which avoids any reduction of the net-section area (see the net-section strength formula (4)).

When the $r_{f}$ ratios of $T+B+N S F$ bolted connections with washers are compared to the ratios of T+NSF screwed connections [2], it is concluded that the seismic behaviour of screws is better. Ratios of screw joints are significantly higher than 1, while ratios of bolts with washers are only slightly higher than 1 (Fig. 26). Consequently, it is also recommended to use screws instead of bolts in dissipative straps of cold formed structures.

Nevertheless, it is believed that more investigations should be devoted to the seismic suitability of $\mathrm{T}+\mathrm{B}+\mathrm{NSF}$ bolted joints with washers. In the present paper, from the results of a few tests, it has been possible to show the relevance washers in the seismic behaviour of joints. More tests should be performed to 
confirm this point and to improve the design of connections with washers. For instance, it can be investigated whether the use of washers in joints of only one row of bolts results in acceptable dissipative intervals.

Finally, it should be pointed out that the problem of the net-section area reduction due to the bolt holes may be solved following the fourth recommendation mentioned above. For example, straps of non constant width can be used. However, this solution is difficult from the manufacturing point of view.

\section{Conclusions}

The present investigation on bolted connections between straps has given results that, in some senses, are similar to the ones obtained in the previous investigation on screwed connections. For instance, here two modes of failure are also observed, the $\mathrm{T}+\mathrm{B}+\mathrm{TS}$ and the $\mathrm{T}+\mathrm{B}+\mathrm{NSF}$ modes, which show different ductility. Both modes are ductile, their displacement ductility ratios are above 2 $\left(r_{d}>2\right)$, but the ductility of the joints that undergo the net-section failure $(\mathrm{T}+\mathrm{B}+\mathrm{NSF})$ is higher than the ductility of the joints that fail bearing $(\mathrm{T}+\mathrm{B}+\mathrm{TS})$. Therefore, regarding the ductility of the joint itself, the $\mathrm{T}+\mathrm{B}+\mathrm{NSF}$ type of joint is preferred.

The main difference with screw joints is that none of the mentioned types of bolted connections are suitable for seismic design. When the failure mode is $\mathrm{T}+\mathrm{B}+\mathrm{NSF}$, the ultimate load is close to the yielding load of the strap, but most of the times below it. As a consequence, these connections would not allow the development of the dissipative action of the strap in an xbraced frame. When the failure is $T+B+T S$, the strength of the connection is even far lower than the yielding load of the strap.

However, the situation improves when washers are used and, consequently, the strength of the connection increases. This is very important for $\mathrm{T}+\mathrm{B}+\mathrm{NSF}$ joints, because this increase in strength is high enough to allow the dissipative yielding of the bracings. Therefore, the use of washers becomes relevant from both the resistance point of view, and the seismic point of view in the case of $\mathrm{T}+\mathrm{B}+\mathrm{NSF}$ bolt joints.

Apart from the ductility of the joints, other questions have been investigated. For example, the measurement of the stiffness of the connections has allowed to conclude that, if an accurate model of the behaviour of the joint is wanted, it should be taken into account that the value of $\mathrm{k}$ before slipping is considerably higher than its value after slipping.

The effectiveness of the Eurocode 3 Part 1-3 in predicting the strength of the joints has also been evaluated. One of the results of this study is that the Eurocode 3 formulas give good predictions of the joint mode of failure. This is very useful in design because, as it has been shown, the mode of failure of joints is a determining factor in relation to performance of dissipative frames. When it comes to the accuracy of the equations prescribed by this code, it should be pointed out that the predictions of the ultimate loads of NSF joints are 
acceptable, althought slightly conservative. The results of the bearing equation are not so good, mainly when applied to joints connected by means of $8 \mathrm{~mm}$ $\Phi$ bolts.

When designing, one way to know whether the use of washers in a particular joint is effective is by means of a calculation formula. Nowadays, there are not specific formulas for bolted connections with washers in Eurocode 3. Due to the relevance of washers in the seismic behaviour of joints, it may be interesting to modify the net-section strength equation to take into account their effect. For instance, it can be investigated whether good predictions of the ultimate load of joints with washers are obtained if the reduction factor is removed from the current version of this equation.

Finally, the last section of the paper contains a list of recommendations for designing bolted joints suitable for seismic construction. In fact, from the results of the tests performed, it can be concluded that it is better to use screws than bolts to connect the straps of a dissipative x-braced frame. However, it is also shown that bolted joints with washers, designed to fail NSF and to keep the maximum available net-section area, allow the dissipative yielding of the strap. The problem is that in the present investigation only a small group of joints are tested with washers, and it is not known whether this type of connections may be good enough for seismic design. Further tests should be carried out to give light to this question.

\section{References}

[1] Hancock GJ, Cold-formed steel structures. Journal of Constructional Steel Research 2003, 59(4): 473-487.

[2] Casafont M, Arnedo A, Roure F, Rodriguez-Ferran A. Experimental testing of joints for seismic design of lightweight structures. Part 1: screwed joints in straps. Thin-Walled Structures, in press.

[3] Pastor N, Rodríguez-Ferran A. Hysteretic modelling of x-braced shear walls. Thin-Walled Structures 2005; 43(10): 1567-1588.

[4] prEN 1998-1. Eurocode 8: Design of structures for earthquake resistance. Part 1. General rules, seismic acions and rules for buildings. CEN European Committee for standardization. Brussels, 2002 (Draft).

[5] Eurocode 3: Design of steel structures - Part 1-3: General rules supplementary rules for cold-formed members and sheeting. CEN European Committee for Standardisation, Brussels, 2004 (Draft).

[6] Morro T, Experimental campaign of shear connections used in light-gauge steel structures, Final Degree Thesis, Universitat Politècnica de Catalunya; 2004 (in Catalan). 
[7] Fernández C, Bolted joints in straps of lightweight structures, Final Degree Thesis, Universitat Politècnica de Catalunya; 2005 (in Spanish).

[8] Yu WW. Cold-Formed Steel Design, $3^{\text {rd }}$ Edition. John Wiley and Sons; 2000.

[9] Bryan ER. The design of bolted joints in cold-formed steel sections. ThinWalled Structures 1993; 16(1-4): 239-262.

[10] Seleim S, LaBoube R. Behaviour of low ductility steels in cold-formed steel connections. Thin-Walled Structures 1996; 25(2): 135-151.

[11] Rogers CA, Hancock GJ. Failure modes of bolted-sheet-steel connections loaded in shear. Journal of Structural Engineering 2000; 126(3): 288-296.

[12] Zadanfarrokh F, Bryan ER. Testing and design of bolted connections in cold formed steel sections. Eleventh International Specialty Conference on Cold-Formed Steel Structures. St. Louis, Missouri, USA, October 20-21, 1992.

[13] Zaharia R, Dubina D. Behaviour of cold formed steel truss bolted joints. Fourth International Workshop on Connections in Steel Structures. Roanoke, USA, October 22-25, 2000.

[14] Rogers CA, Hancock GJ. New bolted connection design formulae for G550 and G300 sheet steels less than $1.0 \mathrm{~mm}$ thick. Research report no R769. Centre for Advanced Structural Engineering. Department of Civil Engineering. The University of Sydney 1998.

[15] Rogers CA, Hancock GJ. Bolted connection tests of thin G550 and G300 sheet steels. Journal of Structural Engineering 1998; 124(7): 798-808.

[16] Rogers CA, Hancock GJ. Bolted connection design for sheet steels less than $1.0 \mathrm{~mm}$ thick. Journal of Constructional Steel Research 1999; 51(2): 123146.

[17] Wallace JA, Schuster RM, LaBoube RA. Testing of bolted cold-formed steel connections in bearing. Final report. Canadian Cold Formed Steel Research Group. Department of Civil Engineering. University of Waterloo 2001.

[18] Wallace JA, Schuster RM, LaBoube RA. Calibrations of bolted cold-formed steel connections in bearing. Final report. American Iron and Steel Institute 2001.

[19] Technical Committee 7. European Recommendations for the Testing of Connections in Profiled Steel Sheeting and Sections. ECCS publication no. 21. May 1983. 